\title{
Modeling the impact of COVID-19 on air quality in southern California: implications for future control policies
}

\author{
Zhe Jiang ${ }^{1,2} \star$, Hongrong Shi ${ }^{1, \star}$, Bin Zhao ${ }^{3}$, Yu Gu${ }^{4}$, Yifang Zhu ${ }^{5}$, Kazuyuki Miyazaki ${ }^{6}$, Xin Lu ${ }^{7}$, Yuqiang Zhang ${ }^{8}$, \\ Kevin W. Bowman ${ }^{4,6}$, Takashi Sekiya ${ }^{9}$, and Kuo-Nan Liou ${ }^{4}$ \\ ${ }^{1}$ Key Laboratory of Middle Atmosphere and Global Environment Observation, Institute of Atmospheric Physics, \\ Chinese Academy of Sciences, Beijing, China \\ ${ }^{2}$ Carbon Neutrality Research Center, Institute of Atmospheric Physics, Chinese Academy of Sciences, Beijing, China \\ ${ }^{3}$ Pacific Northwest National Laboratory, Richland, WA, USA \\ ${ }^{4}$ Joint Institute for Regional Earth System Science and Engineering and Department of Atmospheric and Oceanic Sciences, \\ University of California, Los Angeles, CA, USA \\ ${ }^{5}$ Institute of Environment and Sustainability, University of California, Los Angeles, CA, USA \\ ${ }^{6}$ Jet Propulsion Laboratory, California Institute of Technology, Pasadena, CA, USA \\ ${ }^{7}$ Petrochina North China Gas Marketing Company, Beijing, China \\ ${ }^{8}$ Nicholas School of the Environment, Duke University, Durham, NC, USA \\ ${ }^{9}$ Japan Agency for Marine-Earth Science and Technology, Yokohama, Japan \\ These authors contributed equally to this work.
}

Correspondence: Hongrong Shi (shihrong@mail.iap.ac.cn) and Bin Zhao (bin.zhao@pnnl.gov)

Received: 19 November 2020 - Discussion started: 29 December 2020

Revised: 10 April 2021 - Accepted: 4 May 2021 - Published: 9 June 2021

\begin{abstract}
In response to the coronavirus disease of 2019 (COVID-19), California issued statewide stay-at-home orders, bringing about abrupt and dramatic reductions in air pollutant emissions. This crisis offers us an unprecedented opportunity to evaluate the effectiveness of emission reductions in terms of air quality. Here we use the Weather Research and Forecasting model with Chemistry (WRF-Chem) in combination with surface observations to study the impact of the COVID-19 lockdown measures on air quality in southern California. Based on activity level statistics and satellite observations, we estimate the sectoral emission changes during the lockdown. Due to the reduced emissions, the population-weighted concentrations of fine particulate matter $\left(\mathrm{PM}_{2.5}\right)$ decrease by $15 \%$ in southern California. The emission reductions contribute $68 \%$ of the $\mathrm{PM}_{2.5}$ concentration decrease before and after the lockdown, while meteorology variations contribute the remaining $32 \%$. Among all chemical compositions, the $\mathrm{PM}_{2.5}$ concentration decrease due to emission reductions is dominated by nitrate and primary components. For $\mathrm{O}_{3}$ concentrations, the emission reductions cause a decrease in rural areas but an increase in
\end{abstract}

urban areas; the increase can be offset by a $70 \%$ emission reduction in anthropogenic volatile organic compounds (VOCs). These findings suggest that a strengthened control on primary $\mathrm{PM}_{2.5}$ emissions and a well-balanced control on nitrogen oxides and VOC emissions are needed to effectively and sustainably alleviate $\mathrm{PM}_{2.5}$ and $\mathrm{O}_{3}$ pollution in southern California.

\section{Introduction}

Anthropogenic emissions from various emission sources, including transportation, industrial, agricultural, residential, and commercial sectors, contribute to California's longexisting air pollution problems (e.g., Shirmohammadi et al., 2016; Hong et al., 2015; Warneke et al., 2013). The major pollutants include, but are not limited to, fine particulate matter $\left(\mathrm{PM}_{2.5}\right)$, nitrogen dioxide $\left(\mathrm{NO}_{2}\right)$, sulfur dioxide $\left(\mathrm{SO}_{2}\right)$, and ozone $\left(\mathrm{O}_{3}\right)$. Exposure to these pollutants has been correlated with an increased rate of morbidity and mortality (Wang et al., 2019). Mitigating the adverse effects of air pollution by 
reducing air pollutant emissions from major sectors has been and will continue to be a major public policy challenge. However, the effect of emission reductions from various sources on air quality improvement is subject to substantial uncertainties because such effects cannot be directly measured and because the atmospheric chemistry processes are highly nonlinear and complicated (Zhao et al., 2019b, 2015; Chen et al., 2013). The recent coronavirus disease of 2019 (COVID19) provides an unprecedented opportunity for a more robust understanding of the environmental impacts brought by the emission reductions.

More than 200 countries and territories around the world have reported a total of about 53 million confirmed cases of COVID-19 that originated from Wuhan, China, and a death toll of more than 1300000 (World Health Organization, 2020). California is one of the most affected states in the United States (US), partly because its poor air quality makes Californians more susceptible to infectious diseases such as COVID-19 (Bashir et al., 2020; Copat et al., 2020). In response to the emergence of COVID-19, statewide stayat-home orders and related actions (e.g., closure of nonessential businesses) took effect on 19 March 2020 in California. These orders are expected to reduce vehicle traffic and industrial activities, thereby changing the air pollutant emissions and air quality in the state. It is essential to obtain a high-spatiotemporal-resolution estimation of air pollution for a better understanding of the atmospheric impacts caused by changes in anthropogenic activity associated with the COVID-19 pandemic.

A number of studies emerged soon after the start of the COVID-19 pandemic and the subsequent lockdown to assess the impact of the pandemic on air quality over various regions around the world. For example, Archer et al. (2020) compared the observed concentrations at all available ground monitoring sites in the US between April 2020 and the prior 5 years (2015-2019) and found statistically significant decreases in $\mathrm{NO}_{2}$ concentrations at more than $65 \%$ of the monitoring sites, with an average drop of 2 ppb. Pan et al. (2020) compared the surface air quality monitoring data in California during the period 20 March-5 May 2020 with those in 2015-2019 and found that $\mathrm{PM}_{2.5}$ in 2020 exhibited a notable decrease, which could result from emission reductions associated with the COVID-19 lockdown. Similar findings, i.e., reduced $\mathrm{PM}_{2.5}$ and $\mathrm{NO}_{2}$ concentrations, are also reported for China (e.g., Chu et al., 2021; Le et al., 2020; Liu et al., 2020; Marlier et al., 2020; Shi and Brasseur, 2020; Miyazaki et al., 2020b), India (e.g., Pathakoti et al., 2020; Sharma et al., 2020), and Europe (e.g., Chen et al., 2020; Menut et al., 2020; Sicard et al., 2020; Ordóñez et al., 2020) based on surface and/or satellite observations. For $\mathrm{O}_{3}$, the concentrations either increased or slightly decreased during the pandemic, depending on the region (Bekbulat et al., 2020; Huang et al., 2021; Pan et al., 2020; Zhao et al., 2020). Most of the above studies, however, are limited to comparing observations with and without lockdown measures, which correspond to different time periods under different meteorological conditions.

Meteorology plays significant roles in air pollution formation, transport, deposition, and transformation (P. Wang et al., 2020), which is a very important factor that affects concentrations of $\mathrm{O}_{3}$ and $\mathrm{PM}_{2.5}$ (Stewart et al., 2017). The changes in air quality due to meteorological variations may obscure the effects of emission changes during the COVID-19 lockdown. Using the Community Multiscale Air Quality model, P. Wang et al. (2020) showed that the benefits of emission reductions were overwhelmed by adverse meteorology over the North China Plain, and severe air pollution events were thus not avoided. Goldberg et al. (2020) reported that meteorological patterns were especially favorable for low $\mathrm{NO}_{2}$ in much of the United States in spring 2020, complicating comparisons with spring 2019; meteorological variations between years can cause $\sim 15 \%$ differences in monthly mean column $\mathrm{NO}_{2}$. In view of this, a modeling approach is necessary to accurately assess the impact of lockdown measures by excluding the possible effects of meteorological conditions and to examine the possible mechanisms responsible for the changes in the air pollutant concentrations. In addition, while previous studies have evaluated air quality changes in different regions due to the emission reductions associated with the COVID-19 lockdown, it remains unclear how the COVID19-induced emission reductions and the concurrent meteorological variations influence air quality in California.

The objective of this study is to investigate the air quality impact of the emission reductions in southern California in association with COVID-19 by employing high-resolution atmospheric modeling in combination with surface observations. Based on the statistics of activity levels together with constraints from satellite observations, we estimate the sectoral emission changes during the COVID-19 lockdown. We then conduct model simulations using the Weather Research and Forecasting model with Chemistry (WRF-Chem) for the periods before and during the COVID-19 lockdown to investigate the effects of reduced emissions and meteorology on air pollution, respectively. Understanding how air quality responds to the emission reductions during the COVID-19 pandemic will provide important insight into the future development and optimization of effective air pollution control strategies in southern California.

\section{Method and data}

\subsection{Model configuration and emission estimation}

We simulate the impact of COVID-19 lockdown measures on air quality using the WRF-Chem version 3.9.1, which considers highly nonlinear and complex meteorological and atmospheric chemistry processes. The simulation period is 18 February to 23 April 2020, which includes about 1 month before and after the California governor issued the stay-at- 
home (lockdown) order on 19 March (Pan et al., 2020). We apply the model to two nested domains: Domain 1 covers the western United States and its surrounding areas at a $12 \mathrm{~km} \times 12 \mathrm{~km}$ horizontal resolution; Domain 2 covers California with a $4 \mathrm{~km} \times 4 \mathrm{~km}$ resolution (Fig. 1). We focus our analysis on southern California (the red rectangle in Fig. 1), the largest metropolitan area in California, which is significantly affected by the lockdown measures. We classify model grids in southern California into urban and rural areas to facilitate the analysis of $\mathrm{O}_{3}$ simulation results. To be classified as urban, an area in the US needs to have a population density of 1000 people per square mile (Ratcliffe et al., 2016), i.e., about 6000 people per $4 \mathrm{~km} \times 4 \mathrm{~km}$ model grid. As we focus our analysis on southern California, one of the most densely populated areas in the US, we use a higher population density threshold of 30000 people per model grid to better distinguish areas with different photochemistry regimes (Fig. S1 in the Supplement). We employ an extended Carbon Bond 2005 (CB05) (Yarwood et al., 2005) with chlorine chemistry (Sarwar et al., 2008) coupled with the Modal for Aerosol Dynamics in Europe volatility basis set (MADE VBS) (K. Wang et al., 2015; Ahmadov et al., 2012). MADE VBS uses a modal aerosol size representation and an advanced secondary organic aerosol (SOA) module based on the VBS approach. The aqueous-phase chemistry is based on the AQChem module used in the Community Multiscale Air Quality (CMAQ) model (K. Wang et al., 2015). The chemical initial and boundary conditions were extracted from the output of the Whole Atmosphere Community Climate Model (WACCM) (Marsh et al., 2013). A $6 \mathrm{~d}$ spin-up period is used to minimize the influence of initial conditions on simulation results. The vertical resolution, meteorological initial and boundary conditions, and physical options are the same as our previous modeling studies based on WRF-Chem for California (Zhao et al., 2019a; T. Y. Wang et al., 2020; Shi et al., 2019).

We obtain anthropogenic emissions in California without the influence of COVID-19 lockdown measures from the California Air Resources Board (CARB) for 2012, the latest year for which data are available (California Air Resources Board, 2018). We scale the 2012 emissions to 2020 levels by employing the relative changes for 2012-2018 in California from the National Emissions Inventory (NEI) trend report (US Environmental Protection Agency, 2018a) and assuming that the trends continued during 2018-2020. The anthropogenic emissions outside California are derived from the National Emission Inventory (US Environmental Protection Agency, 2018b) in 2011 and are scaled to 2020 following the same method. The biogenic, wind-blown dust, sea salt, and wildfire emissions are calculated online in WRFChem, as detailed in our previous studies (Zhao et al., 2019a;

T. Y. Wang et al., 2020; Shi et al., 2019).

In our baseline simulation (Base scenario in Table 1), we use the above emission inventories. To evaluate the effect of the COVID-19 response actions, we conduct another simu-

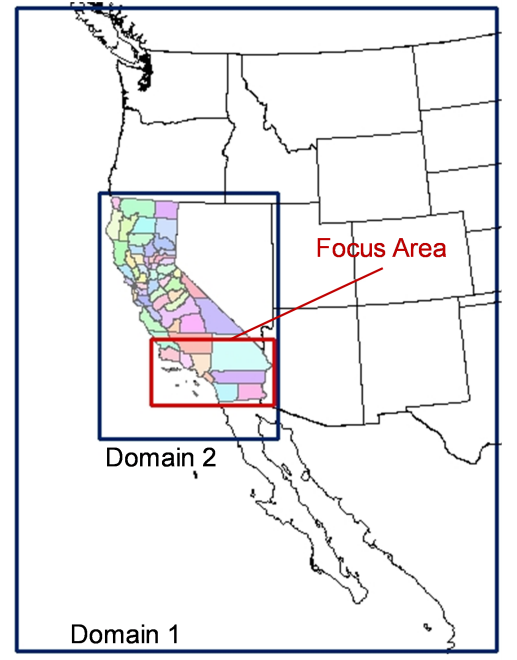

Figure 1. Simulation domains in this study. The red rectangle denotes the area of southern California where most analyses in this study are focused.

lation (Lockdown scenario in Table 1) in which the CARB anthropogenic emission inventory after 19 March is adjusted to account for the emission changes due to the COVID-19 lockdown. Because of the lack of detailed emission data, which often take years to update, we rely on a number of key activity indicators to estimate the sector-specific relative changes in anthropogenic emissions (as summarized in Table 2), which are subsequently evaluated against satellitederived emission estimates. For the transportation sector, we separately estimate the reduction rates for on-road, offroad, and aircraft emissions due to the COVID-19 lockdown. Specifically, we assume the reduction rates in gasoline and diesel vehicle emissions in the on-road sector to be the same as the reduction rates in gasoline and diesel production from the pre-lockdown period to the lockdown period, as documented by the California Energy Commission's Weekly Fuels Watch Reports (California Energy Commission, 2020b). We then estimate the reduction rates in total emissions from the on-road sector based on the relative fractions of gasoline and diesel vehicle emissions reported by the CARB emission inventory. Since the off-road sector involves few gasoline vehicles, we assume the reduction rates in off-road emissions to be the same as the reduction rate in diesel production. For the aircraft sector, we assume the reduction rates in aircraft emissions to be the same as the reduction rate in jet fuel production from the Weekly Fuels Watch Reports (California Energy Commission, 2020b). The changes in emissions from the industrial, residential, and commercial sectors are assumed to be proportional to the changes in electricity consumption by the corresponding sector, as summarized in the Energy Insights Reports of the California Energy Commission (California Energy Commission, 2020a). The changes in emissions from power plants are estimated as a 
Table 1. Summary of model scenarios developed in this study.

\begin{tabular}{|c|c|}
\hline Scenario & Definition \\
\hline Base & $\begin{array}{l}\text { This scenario uses the default CARB emission inventory without considering the emis- } \\
\text { sion reductions induced by the COVID- } 19 \text { lockdown. It provides a baseline for evaluat- } \\
\text { ing the effect of COVID-19 lockdown on air quality. }\end{array}$ \\
\hline Lockdown & $\begin{array}{l}\text { This scenario adjusts the CARB emission inventory to account for the emission reduc- } \\
\text { tions due to the COVID-19 lockdown. The difference between Base and Lockdown } \\
\text { represents the effect of the COVID-19 lockdown. }\end{array}$ \\
\hline VOC1.0 & $\begin{array}{l}\text { This scenario is the same as Lockdown except that the VOC emissions are kept at the } \\
\text { level of the Base scenario. It is used to evaluate the relative contribution of VOC and } \\
\mathrm{NO}_{x} \text { reductions to COVID-19-induced } \mathrm{O}_{3} \text { concentration changes. }\end{array}$ \\
\hline $\mathrm{NO}_{x} 0.3$ & $\begin{array}{l}\text { This scenario is the same as Lockdown except that the } \mathrm{NO}_{x} \text { emissions are further re- } \\
\text { duced to } 30 \% \text { of those in the Base scenario. It is used to assess the potential effects of } \\
\text { strengthened } \mathrm{NO}_{x} \text { control measures. }\end{array}$ \\
\hline VOC0.3 & $\begin{array}{l}\text { This scenario is the same as Lockdown except that the VOC emissions are further re- } \\
\text { duced to } 30 \% \text { of those in the Base scenario. It is used to assess the potential effects of } \\
\text { strengthened VOC control measures. }\end{array}$ \\
\hline
\end{tabular}

Table 2. The percentage of changes in air pollutant emissions during the COVID-19 lockdown relative to a hypothetical scenario without the lockdown in southern California.

\begin{tabular}{lrrrrrrr}
\hline & $\mathrm{VOC}$ & $\mathrm{CO}$ & $\mathrm{NO}_{x}$ & $\mathrm{SO}_{x}$ & $\mathrm{PM}_{10}$ & $\mathrm{PM}_{2.5}$ & $\mathrm{NH}_{3}$ \\
\hline On-road transportation & $-50 \%$ & $-51 \%$ & $-39 \%$ & $-35 \%$ & $-44 \%$ & $-42 \%$ & $-51 \%$ \\
Off-road transportation & $-30 \%$ & $-30 \%$ & $-30 \%$ & $-30 \%$ & $-30 \%$ & $-30 \%$ & $-30 \%$ \\
Aircraft & $-70 \%$ & $-70 \%$ & $-70 \%$ & $-70 \%$ & $-70 \%$ & $-70 \%$ & $-70 \%$ \\
Power plants & $-7 \%$ & $-7 \%$ & $-7 \%$ & $-7 \%$ & $-7 \%$ & $-7 \%$ & $-7 \%$ \\
Industrial & $-15 \%$ & $-15 \%$ & $-15 \%$ & $-15 \%$ & $-15 \%$ & $-15 \%$ & $-15 \%$ \\
Residential & $10 \%$ & $10 \%$ & $10 \%$ & $10 \%$ & $10 \%$ & $10 \%$ & $10 \%$ \\
Commercial & $-15 \%$ & $-15 \%$ & $-15 \%$ & $-15 \%$ & $-15 \%$ & $-15 \%$ & $-15 \%$ \\
Agriculture & $0 \%$ & $0 \%$ & $0 \%$ & $0 \%$ & $0 \%$ & $0 \%$ & $0 \%$ \\
Total & $-21.1 \%$ & $-35.7 \%$ & $-28.3 \%$ & $-18.5 \%$ & $-9.7 \%$ & $-15.0 \%$ & $-16.1 \%$ \\
\hline
\end{tabular}

function of the total electricity demand in California (California Energy Commission, 2020a). We also checked the emission change for power plants measured by the Continuous Emission Monitoring System (CEMS). There are certain differences between the emission reduction rates estimated based on the CEMS and electricity demand, but the difference only results in a less than $1 \%$ difference in the total emissions of any pollutant (from $0.05 \%$ to $1 \%$ ), which is expected to have a limited effect on the simulation results for mean air pollutant concentrations in southern California (see details in the Supplement and Fig. S3). Having estimated the emission changes using the preceding bottom-up method, in order to prove the reliability of our bottom-up emissions, we compare the changes in nitrogen oxide $\left(\mathrm{NO}_{x}\right)$ emissions with a top-down satellite-based emission inventory - an extended calculation of the Tropospheric Chemistry Reanalysis version 2 (TCR-2) (Miyazaki et al., 2020a). This data product has been obtained from the assimilation of multiple satellite measurements of ozone, $\mathrm{CO}, \mathrm{NO}_{2}, \mathrm{HNO}_{3}$, and $\mathrm{SO}_{2}$ from the OMI (Ozone Monitoring Instrument), TROPOMI (TROPOspheric Monitoring Instrument), MLS (Microwave Limb Sounder), and MOPITT (Measurement Of Pollution In The Troposphere) satellite instruments. The reanalysis calculation for the COVID-19 time period was conducted at $0.56^{\circ}$ horizontal resolution using the global chemical transport model MIROC-CHASER (Watanabe et al., 2011) and an ensemble Kalman filter technique that optimizes chemical concentrations of various species and emissions of $\mathrm{NO}_{x}$, $\mathrm{SO}_{2}$, and $\mathrm{CO}$. The extended reanalysis data for 2020 have already been used by Miyazaki et al. (2020b) to study the air quality response to the Chinese COVID-19 lockdown measures. Here we use the $\mathrm{NO}_{x}$ emission product, which has a sufficiently high quality on the spatiotemporal scales of interest for this study. Using this product, we first calculate $\mathrm{NO}_{x}$ emissions in a hypothetical scenario without considering the COVID-19 effect. Here the hypothetical emission trend in 2020 is averaged from those trends from the top-down $\mathrm{NO}_{x}$ emission inventory in prior years (2017-2019). We subse- 


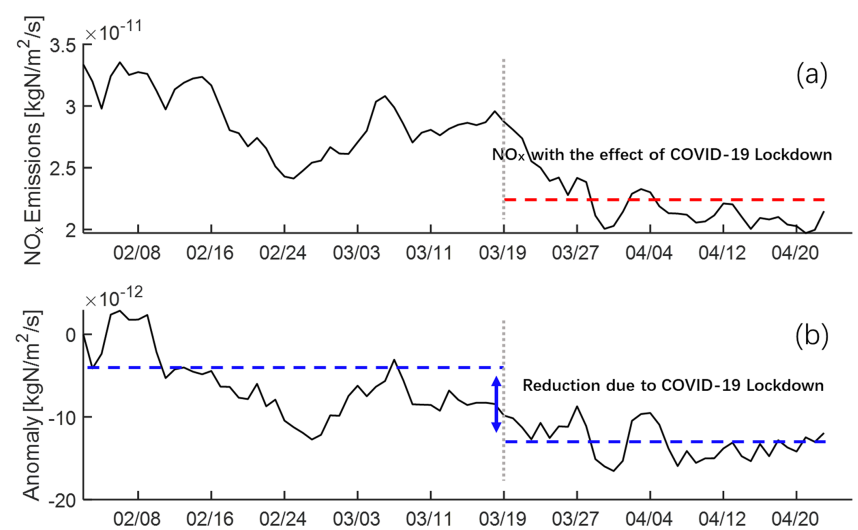

Figure 2. Satellite-derived $\mathrm{NO}_{x}$ emission estimates in southern California. (a) Daily $\mathrm{NO}_{x}$ emissions from 1 February to 23 April 2020. The red line represents the average emissions during the period after 19 March. (b) $\mathrm{NO}_{x}$ emission changes due to COVID-19 (i.e., the anomaly), which are quantified using the difference between the real-world $\mathrm{NO}_{x}$ emissions and the emissions in a hypothetical scenario without considering COVID-19. The emissions in the hypothetical scenario are estimated based on emission trends in prior years (2017-2019) using 1 February as a reference. The difference between two blue dashed lines represents the average reductions of $\mathrm{NO}_{x}$ emissions induced by the COVID-19 lockdown measures that took effect on 19 March. The local valley between 24 February and 3 March is caused by retrieval uncertainties due to unfavorable meteorology conditions and is thus excluded when we estimate the average $\mathrm{NO}_{x}$ emissions before the lockdown.

quently quantify the emission changes due to COVID-19 using the difference between the hypothetical and real-world emissions (see details in Fig. 2). The estimated $\mathrm{NO}_{x}$ reduction ratio induced by the COVID-19 lockdown measures averaged during 19 March to 23 April in southern California is $27.2 \%$ based on the top-down method, which is in good agreement with the $28.3 \%$ (see Table 2) reduction estimated based on the bottom-up method. That said, we acknowledge that, since more detailed data to support a more accurate estimation are not yet available, the estimates of the sector-specific relative changes in emissions inevitably involve some degree of uncertainty, which can be improved in future work.

\subsection{Observational data and model evaluation}

We use a series of meteorology and air quality observations to evaluate the model performance and help analyze the influence of the COVID-19 lockdown. For meteorology, we use observational data obtained from the National Climatic Data Center (NCDC), from which hourly or $3 \mathrm{~h}$ observations of wind speed at $10 \mathrm{~m}$ (WS10), temperature at $2 \mathrm{~m}$ (T2), and water vapor mixing ratio at $2 \mathrm{~m}(\mathrm{Q} 2)$ are available for 82 sites distributed southern California (the red rectangle in Fig. 1). We compare the WRF-Chem meteorological simulations with these measurements and apply a number of statis- tical indices defined in Emery et al. (2001) to quantitatively evaluate the model performance, as summarized in Table 3. In general, the model simulations agree fairly well with surface meteorological observations. The performance statistics for WS10, T2, and Q2 are all within the benchmark ranges proposed by Emery et al. (2001).

For air quality, we achieve hourly observations of $\mathrm{PM}_{2.5}$, $\mathrm{O}_{3}, \mathrm{NO}_{2}$, and $\mathrm{SO}_{2}$ from CARB (California Air Resources Board, 2020) and use them to evaluate the air quality simulations of WRF-Chem (see the "Results and discussion" section). The observational data are available at 42 sites for $\mathrm{PM}_{2.5}, 63$ sites for $\mathrm{O}_{3}, 48$ sites for $\mathrm{NO}_{2}$, and 12 sites for $\mathrm{SO}_{2}$ in southern California (the red rectangle in Fig. 1) during the simulation period. We do not evaluate the model performance in simulating the chemical composition of $\mathrm{PM}_{2.5}$ because the composition data from major observational networks were not available by the time we completed the present study. Nevertheless, our previous studies using almost the same model configurations showed fairly good agreement with $\mathrm{PM}_{2.5}$ composition observations during January, April, July, and October 2012 (Zhao et al., 2019a; T. Y. Wang et al., 2020).

\section{Results and discussion}

\subsection{Evaluation of the simulated results with surface observations}

In this study, we simulated the major air pollutants using WRF-Chem under two scenarios, Base and Lockdown (Table 1). To evaluate the model performance with regard to the temporal variations in air pollutants, we compared the simulated concentrations of $\mathrm{PM}_{2.5}$, maximum daily $8 \mathrm{~h}$ average (MDA8) $\mathrm{O}_{3}, \mathrm{NO}_{2}$, and $\mathrm{SO}_{2}$ with observational data from $\mathrm{CARB}$ in southern California.

Before the COVID-19 lockdown (18 February to 18 March), results from model simulations under the Base scenario $\left(\right.$ Pre $_{\text {Base }}$ ) capture the magnitude and temporal evolution of the four key air pollutants reasonably well, with normalized mean biases (NMBs) of $11.7 \%, 4.5 \%,-14.4 \%$, and $7.8 \%$ for $\mathrm{PM}_{2.5}, \mathrm{MDA} 8 \mathrm{O}_{3}, \mathrm{NO}_{2}$, and $\mathrm{SO}_{2}$, respectively (Fig. 3). During the COVID-19 lockdown period (19 March to 23 April), compared to the simulations for the Base scenario (Post $t_{\text {Base }}$ ), which overestimates the surface concentrations with NMBs of $28.1 \%, 1.6 \%, 21.4 \%$, and $39.2 \%$ for $\mathrm{PM}_{2.5}, \mathrm{MDA} 8 \mathrm{O}_{3}, \mathrm{NO}_{2}$, and $\mathrm{SO}_{2}$, respectively, the simulated results using the adjusted emission inventory (Post Lockdown $_{\text {) }}$ not only agree better with surface observations for all four air pollutants (with NMBs of $10.6 \%, 1.0 \%,-12.6 \%$, and $-13.1 \%$ for $\mathrm{PM}_{2.5}, \mathrm{MDA} 8 \mathrm{O}_{3}, \mathrm{NO}_{2}$, and $\mathrm{SO}_{2}$, respectively), but also show NMBs generally closer to those during the prelockdown period (Fig. 3). The improvement in model performance is observed for both urban and rural areas. In the urban areas, the NMB for $\mathrm{PM}_{2.5}$ drops from $25.8 \%$ under the 
Table 3. Evaluation of meteorological simulation results compared to observational data from the National Climatic Data Center.

\begin{tabular}{|c|c|c|c|c|c|c|c|}
\hline Variable & Index & Value & $\operatorname{Ref}^{\mathrm{a}}$ & Variable & Index & Value & $\operatorname{Ref}^{\mathrm{a}}$ \\
\hline \multirow[t]{5}{*}{ Wind speed $\left(\mathrm{m} \mathrm{s}^{-1}\right)$} & Mean observation & 3.92 & & \multirow[t]{5}{*}{ Temperature $(\mathrm{K})$} & Mean observation & 287.48 & \\
\hline & Mean simulation & 3.69 & & & Mean simulation & 287.21 & \\
\hline & Mean bias & -0.22 & $\leq \pm 0.5$ & & Mean bias & -0.28 & $\leq \pm 0.5$ \\
\hline & Gross error & 1.43 & $\leq 2$ & & Gross error & 1.76 & $\leq 2$ \\
\hline & $\mathrm{IOA}^{\mathrm{b}}$ & 0.76 & $\geq 0.6$ & & IOA & 0.93 & $\geq 0.8$ \\
\hline \multirow[t]{5}{*}{ Wind direction $\left(^{\circ}\right)$} & Mean observation & 243.45 & & \multirow[t]{5}{*}{ Humidity $\left(\mathrm{g} \mathrm{kg}^{-1}\right)$} & Mean observation & 6.41 & \\
\hline & Mean simulation & 232.90 & & & Mean simulation & 6.16 & \\
\hline & Mean bias & 1.48 & $\leq \pm 10$ & & Mean bias & -0.25 & $\leq \pm 1$ \\
\hline & Gross error & 44.53 & $\leq 30$ & & Gross error & 0.83 & $\leq 2$ \\
\hline & & & & & IOA & 0.84 & $\geq \overline{0} .6$ \\
\hline
\end{tabular}

${ }^{a}$ The reference values are taken from Emery et al. (2001). ${ }^{\mathrm{b}}$ IOA: index of agreement.

Base scenario to $3.9 \%$ under the Lockdown scenario, getting closer to the NMB of $4.0 \%$ during the pre-lockdown period. The corresponding NMB in rural areas drops from $29.7 \%$ to $15.1 \%$, also getting closer to $17.8 \%$ during the prelockdown period (Fig. 3e, g). Regarding $\mathrm{MDA}_{8} \mathrm{O}_{3}$, although the differences between the Base and Lockdown scenarios are quite small (Fig. 3b), the NMB is slightly improved from $-1.5 \%$ (Post Base $_{\text {e }}$ ) to $-0.2 \%$ (Post Lockdown $_{\text {) }}$ in urban areas and from $3.2 \%$ to $1.5 \%$ in rural areas (Fig. 3f, h).

Subsequently, we evaluated the spatial distributions of simulated $\mathrm{PM}_{2.5}$ and MDA8 $\mathrm{O}_{3}$ concentrations using observational data averaged during the pre-lockdown and lockdown periods in southern California (Fig. 4). Figure S4 shows the scattergrams of the simulated and observed monthly average $\mathrm{PM}_{2.5}$ and MDA8 $\mathrm{O}_{3}$ concentrations in southern California. The Base scenario can simulate the spatial patterns of $\mathrm{PM}_{2.5}$ and MDA8 $\mathrm{O}_{3}$ reasonably well (Fig. 4a-b and d-e), but it overestimates the observations of $\mathrm{PM}_{2.5}$ concentrations during the lockdown period (Post ${ }_{\text {Base}}$, Figs. $4 \mathrm{~b}$ and $\mathrm{S} 4 \mathrm{~b}$ ). The simulated distributions of $\mathrm{PM}_{2.5}$ concentrations under the Lockdown scenario (Post Lockdown) match the observations better than those for the Base scenario (Post ${ }_{B a s e}$ ) (Figs. 4b-c and S4b-c); the hot spots occurring over Los Angeles County become less polluted and more consistent with the surface observations after considering the emission reductions associated with the COVID-19 lockdown (Fig. 4b-c).

\subsection{Effects of anthropogenic emission reductions and meteorology conditions on air pollutants}

Both observations and simulations in Fig. 3 show significant changes in air pollutant concentrations during the COVID19 lockdown relative to the pre-lockdown period, resulting from a combination of emission reductions and meteorology variations. Our model simulations allow us to quantify the relative contributions of these two factors. Figure 5a-f illustrate population-weighted concentrations of simulated $\mathrm{PM}_{2.5}$ components, $\mathrm{NO}_{2}, \mathrm{SO}_{2}, \mathrm{MDA} 8 \mathrm{O}_{3}$ in southern California, and MDA $8 \mathrm{O}_{3}$ over the urban and rural areas of southern California under the Base and Lockdown scenarios. We use population-weighted concentrations because they are more relevant to the health impacts of air pollutants $\left(\mathrm{PM}_{2.5}\right.$ and $\mathrm{O}_{3}$ ), the mitigation of which is an ultimate goal of controlling air pollution. Figure $\mathrm{S} 5$ shows the mean concentrations of simulated $\mathrm{PM}_{2.5}$ components, MDA8 $\mathrm{O}_{3}, \mathrm{NO}_{2}$, and $\mathrm{SO}_{2}$ in southern California.

The simulations of the Base and Lockdown scenarios during the lockdown period (Post Base $_{\text {and }}$ Post $t_{\text {Lockdown }}$ ) have the same model configurations and inputs (same largescale meteorological conditions) except for different emission inventories. The concentration differences between the two scenarios during the lockdown period (Post Lockdown $^{-}$ Post $_{\text {Base }}$ ) represent the effect of anthropogenic emission reductions. Strictly speaking, while the large-scale meteorological fields are the same in Post Base $_{\text {and Post }}$ Lockdown, the different emission inputs could cause small differences in regional meteorology fields through the interactions between air pollutants and meteorology. Such a meteorology perturbation is considered to be part of the emission reduction effect because it is fundamentally caused by emission reductions. The simulations of the Base scenario during the lockdown and pre-lockdown periods (Post ${ }_{\text {Base }}$ and Pre $_{\text {Base }}$ ) both use the emission inventories without considering COVID-19-induced emission reductions. The differences between Post $t_{\text {Base }}$ and Pre Base $_{\text {can be regarded as the impact }}$ of meteorology variations. Here our intention is to examine the relative contribution of meteorological variations to the population-weighted air pollutant concentrations before and after the lockdown instead of the changes relative to the climatological conditions. However, we acknowledge that it is more meaningful and informative to assess the meteorological effect by conducting ensemble simulations over multiple years or using multiyear averaged meteorological conditions to serve as a reference state (Le et al., 2020), which warrants further studies in the future. Figures 6 and 7 further show 

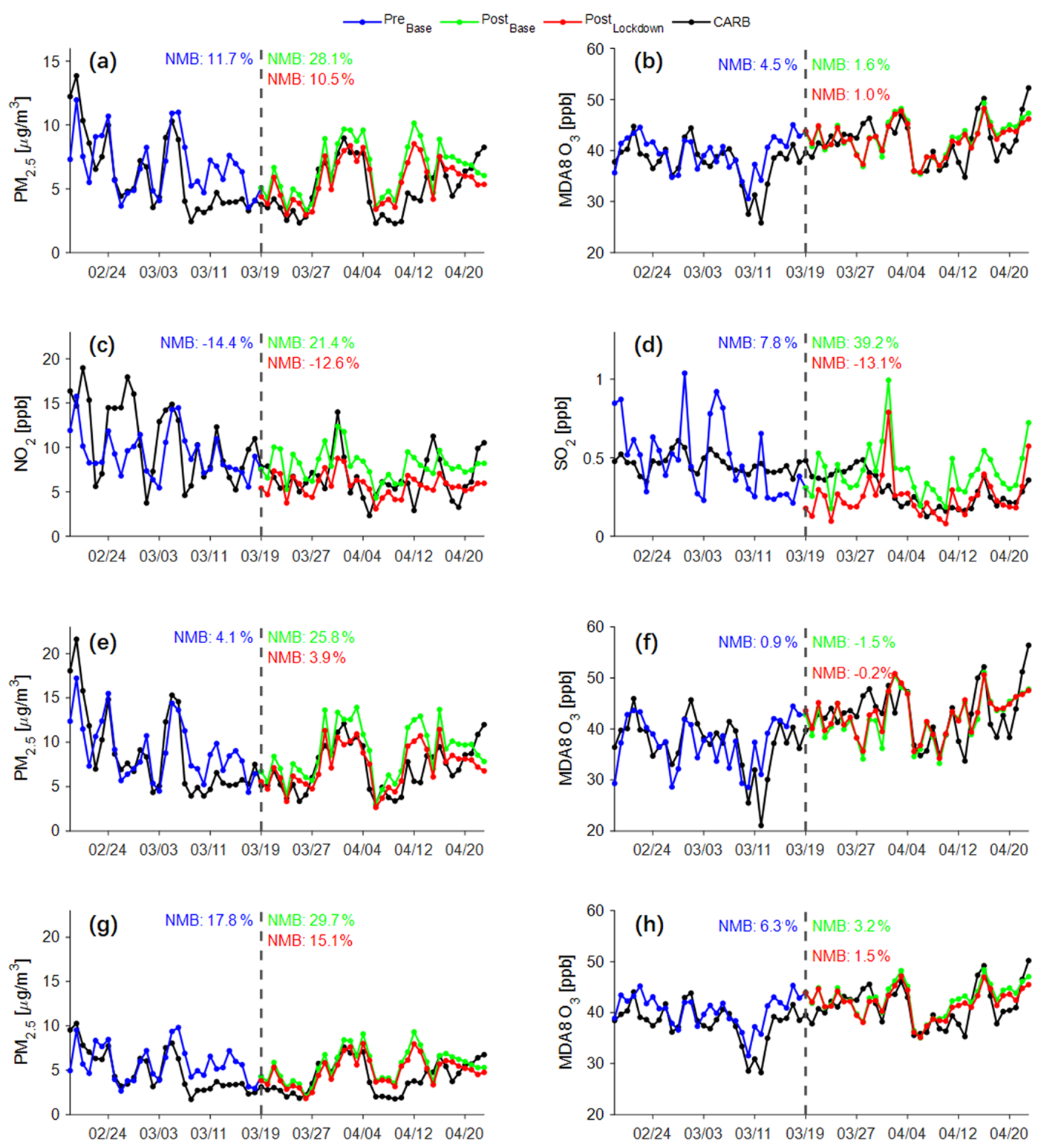

Figure 3. Time series of observed and simulated concentrations of major pollutants. (a-d) Time series of (a) $\mathrm{PM}_{2.5}$, (b) $\mathrm{MDA}_{8} \mathrm{O}_{3}$, (c) $\mathrm{NO}_{2}$, and (d) $\mathrm{SO}_{2}$ averaged across all observational stations from CARB over southern California. (e-f) Time series of (e) PM 2.5 and (f) $\mathrm{MDA}_{8}$ $\mathrm{O}_{3}$ across all stations over the urban areas of southern California. (g-h) The same as (e)-(f) but for the rural areas. Black lines are surface observations from the CARB network. Blue, green, and red lines are simulated air pollutant concentrations during the pre-lockdown period

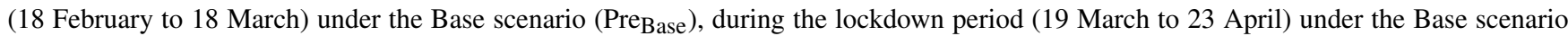

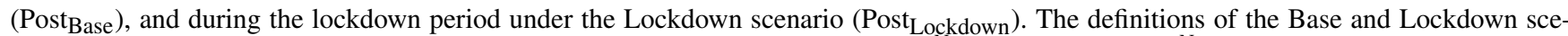
narios are summarized in Table 1 . Normalized mean bias (NMB) is given by $=\sum_{i=1}^{N}\left(\operatorname{Var}_{\mathrm{m}}-\operatorname{Var}_{\mathrm{o}}\right) / \sum_{i=1}^{N} \operatorname{Var}_{\mathrm{o}}$, where $N$ is the number of sites, and $\operatorname{Var}_{\mathrm{m}}$ and $\operatorname{Var}_{\mathrm{o}}$ are modeled and observed concentrations, respectively.

the spatial distribution of the concentration changes caused by anthropogenic emission reductions and meteorology variations.

The simulated population-weighted $\mathrm{NO}_{2}$ concentrations during the lockdown decrease by $4.3 \mathrm{ppb}$ (from 10.7 to $6.4 \mathrm{ppb}$ ) relative to the pre-lockdown period, to which the anthropogenic emission reductions and meteorology conditions contribute $2.4 \mathrm{ppb}(56 \%)$ and $1.9 \mathrm{ppb}(44 \%)$, respectively
(Fig. 5b). The decrease in $\mathrm{NO}_{2}$ concentrations as a result of the anthropogenic emission reductions $(27 \%)$ is similar to the reduction ratio in $\mathrm{NO}_{x}$ emissions (28\%), indicating that the $\mathrm{NO}_{x}$ emission reductions can be almost fully transferred to ambient concentrations. According to our emission estimation, over $80 \%$ of the $\mathrm{NO}_{x}$ reductions is attributed to the substantially lowered traffic intensity due to the stay-at-home order. Note that the soil $\mathrm{NO}_{x}$ emissions are not taken into 

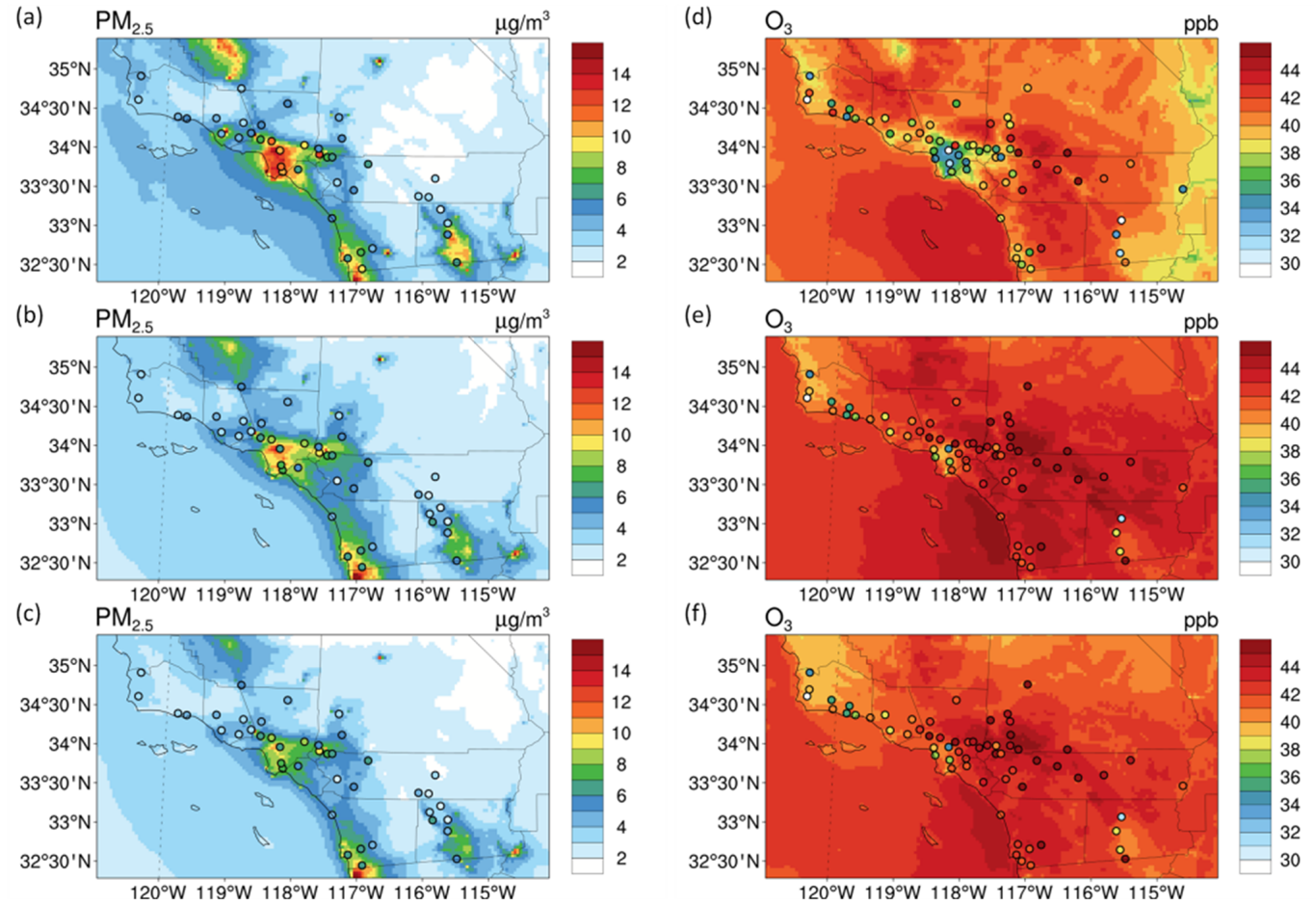

Figure 4. Overlay plots of the simulated (contour) and observed (circles) $\mathrm{PM}_{2.5}$ and $\mathrm{MDA} 8 \mathrm{O}_{3}$ concentrations in southern California. Panels (a)-(c) are for $\mathrm{PM}_{2.5}$ and (d)-(f) are for MDA8 $\mathrm{O}_{3}$. Panels (a) and (d) are for the pre-lockdown period (18 February to 18 March) under the Base scenario (Pre Base); (b) and (e) are for the lockdown period (19 March to 23 April) under the Base scenario (PostBase); (c) and (f) are for the lockdown period under the Lockdown scenario (Post Lockdown).
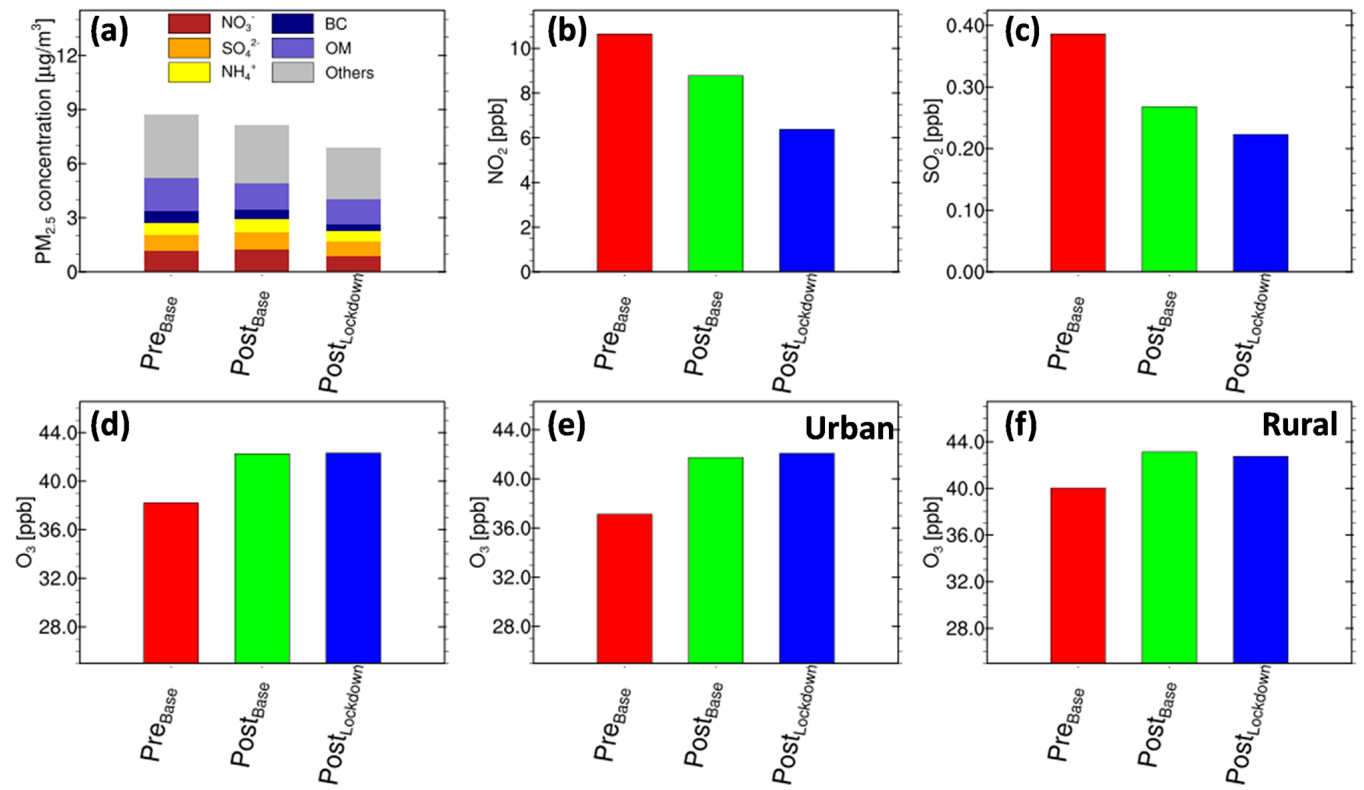

Figure 5. Effects of emission reductions and meteorology conditions on air pollutants. (a-d) Population-weighted concentrations of simulated air pollutant concentrations in southern California: (a) $\mathrm{PM}_{2.5}$ components; (b) $\mathrm{NO}_{2}$; (c) $\mathrm{SO}_{2}$; (d) MDA8 $\mathrm{O}_{3}$ over southern California; (e) MDA8 $\mathrm{O}_{3}$ over the urban areas of southern California; (f) MDA8 $\mathrm{O}_{3}$ over the rural areas of southern California. Pre Base, Post $_{\mathrm{Base}}$, and Post $_{\text {Lockdown }}$ have the same meanings as in Fig. 3. 

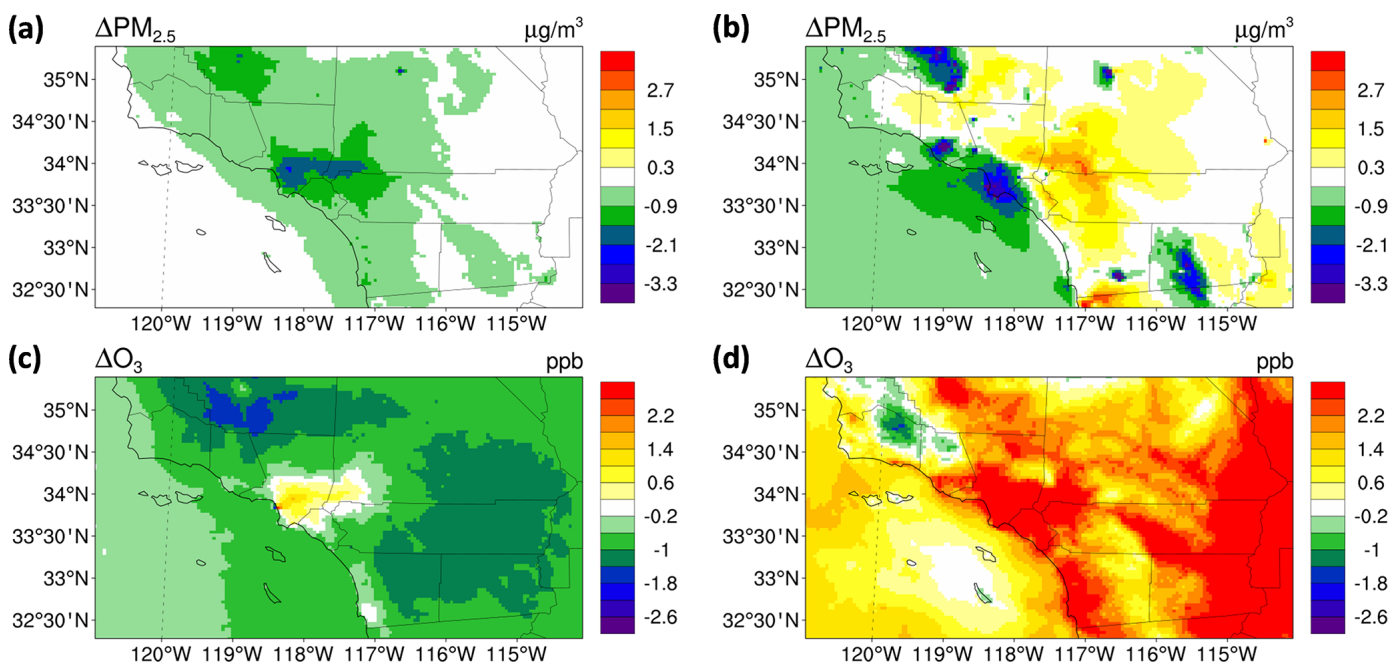

Figure 6. Spatial distributions of the emission reductions and meteorology condition effects on air pollutants. (a, c) Emission reductions and $(\mathbf{b}, \mathbf{d})$ meteorology variations in $(\mathbf{a}, \mathbf{b}) \mathrm{PM}_{2.5}$ and $(\mathbf{c}, \mathbf{d}) \mathrm{MDA} 8 \mathrm{O}_{3}$ concentrations.

account in our WRF-Chem simulation. According to Guo et al. (2020), the total soil $\mathrm{NO}_{x}$ emissions in California account for only about $1.1 \%$ of the state's total anthropogenic $\mathrm{NO}_{x}$ emissions (California Air Resources Board, 2017). The soil $\mathrm{NO}_{x}$ emissions in southern California are generally even lower compared to other parts of the state (Guo et al., 2020). Since our study focuses on the impact of anthropogenic emission reductions on air quality during the COVID-19 lockdown period, the absence of soil $\mathrm{NO}_{x}$ emissions has little impact on our main results and will not change the main findings of this study. The population-weighted concentrations of $\mathrm{SO}_{2}$ also show a decreasing trend (Fig. 5c). Compared with $\mathrm{NO}_{2}$, the decrease in $\mathrm{SO}_{2}$ concentrations due to emission reductions is smaller (17\%), partly because power generators and heavy industry (the main sources of $\mathrm{SO}_{2}$ ) are less affected by the COVID-19 lockdown (see Table 2).

Coinciding with the decrease in $\mathrm{NO}_{2}$ and $\mathrm{SO}_{2}$, the simulated population-weighted $\mathrm{PM}_{2.5}$ concentrations decrease by $1.8 \mu \mathrm{g} \mathrm{m}^{-3}$ from $8.7 \mu \mathrm{g} \mathrm{m}^{-3}$ during the pre-lockdown period $\left(\right.$ Pre $_{\text {Base }}$ ) to $6.9 \mu \mathrm{g} \mathrm{m}^{-3}$ during the lockdown pe-

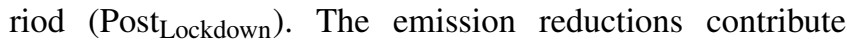
$1.2 \mu \mathrm{g} \mathrm{m}^{-3}(67 \%)$ of the above decrease, which translates into a $15 \%$ reduction in population-weighted $\mathrm{PM}_{2.5}$ concentrations from the levels without the lockdown (i.e., Post Base$_{\text {) }}$ ) (Fig. 5a). The decrease occurs almost everywhere across the domain (Fig. 6a), consistent with the results in the last section that $\mathrm{PM}_{2.5}$ concentrations are lowered in both urban and rural areas as a result of the emission reductions (Fig. 3e, $\mathrm{g})$. The concentration decrease is higher in urban areas than in rural areas (Figs. 6a and 3e, g), with the most significant decline occurring in urban areas of Los Angeles County (Fig. 6a). In contrast, the meteorology variations can increase the $\mathrm{PM}_{2.5}$ concentrations in some regions (mainly the inland regions) and decrease them in others (mainly the coastal re- gions) (Fig. 6b). The net effect is to reduce the populationweighted concentration by $0.6 \mu \mathrm{g} \mathrm{m}^{-3}$ since the concentration decrease happens to occur in more densely populated regions (Fig. 5a).

The concentrations of $\mathrm{PM}_{2.5}$ are affected by emissions of multiple pollutants through both primary emissions and chemical reactions. To further explore the reasons behind the $\mathrm{PM}_{2.5}$ concentration changes, we examine the changes in individual chemical components, as shown in Figs. 5a and 7. Following the emission changes (from Post Base $_{\text {to }}$ Post $_{\text {Lockdown }}$ ), all major $\mathrm{PM}_{2.5}$ components experience a concentration decrease throughout almost the entire domain (Fig. 7), since the emissions of essentially all pollutants are reduced to some extent due to the lockdown measures (Table 2). The population-weighted concentrations of nitrate decrease the most $\left(0.42 \mu \mathrm{g} \mathrm{m}^{-3}\right)$, followed by "others" $\left(0.32 \mu \mathrm{g} \mathrm{m}^{-3}\right.$, including all other components besides the key components listed here), organic matter (OM, $\left.0.16 \mu \mathrm{g} \mathrm{m}^{-3}\right)$, ammonium $\left(0.15 \mathrm{\mu g} \mathrm{m}^{-3}\right)$, black carbon (BC, $\left.0.10 \mu \mathrm{g} \mathrm{m}^{-3}\right)$, and sulfate (from $0.07 \mu \mathrm{g} \mathrm{m}^{-3}$ ) (Fig. 5a). The largest decrease in nitrate is tied to the substantial reduction in $\mathrm{NO}_{x}$ emissions, which is further explained by a larger reduction ratio in transportation emissions (by 30\%-70\%) compared to other emission sources (Table 2). In addition, the decreases in others, elemental carbon (EC), and primary OM (a fraction of the total $\mathrm{OM}$ ) are attributable to the reductions in primary $\mathrm{PM}_{2.5}$ emissions. In our emission estimates, the sectorspecific relative emission changes of EC, primary OM, and others are assumed to be the same as the total primary $\mathrm{PM}_{2.5}$, as summarized in Table 2. For the total emissions of all sectors, the reductions in EC, primary $\mathrm{OM}$, and others are $22.7 \%, 15.8 \%$, and $13.5 \%$, respectively, which are slightly different from the reduction in total primary $\mathrm{PM}_{2.5}$ since different chemical components have different sectoral dis- 

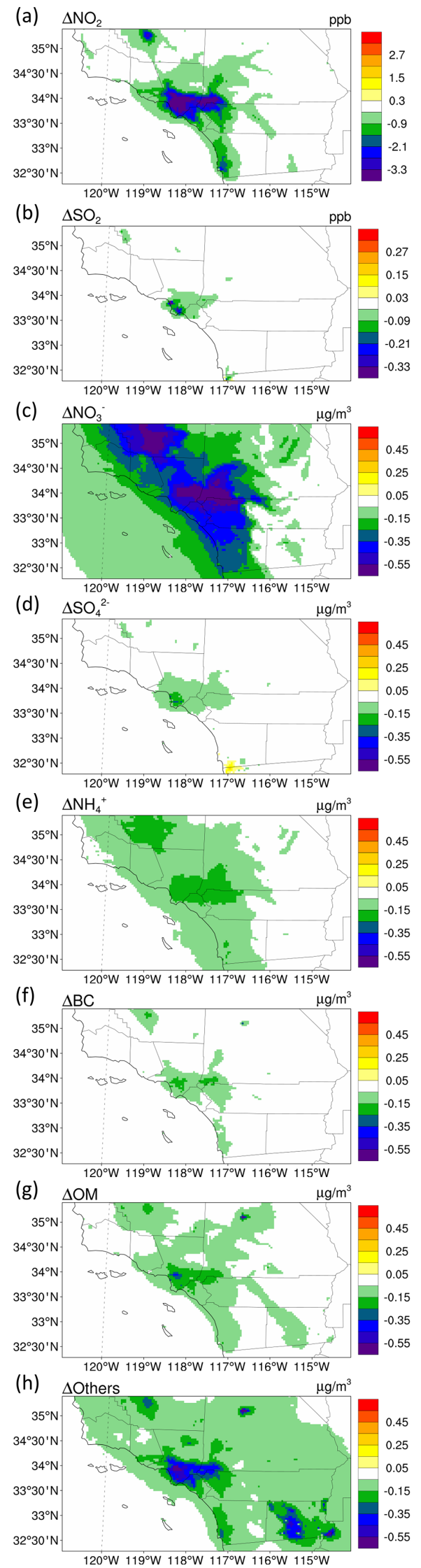
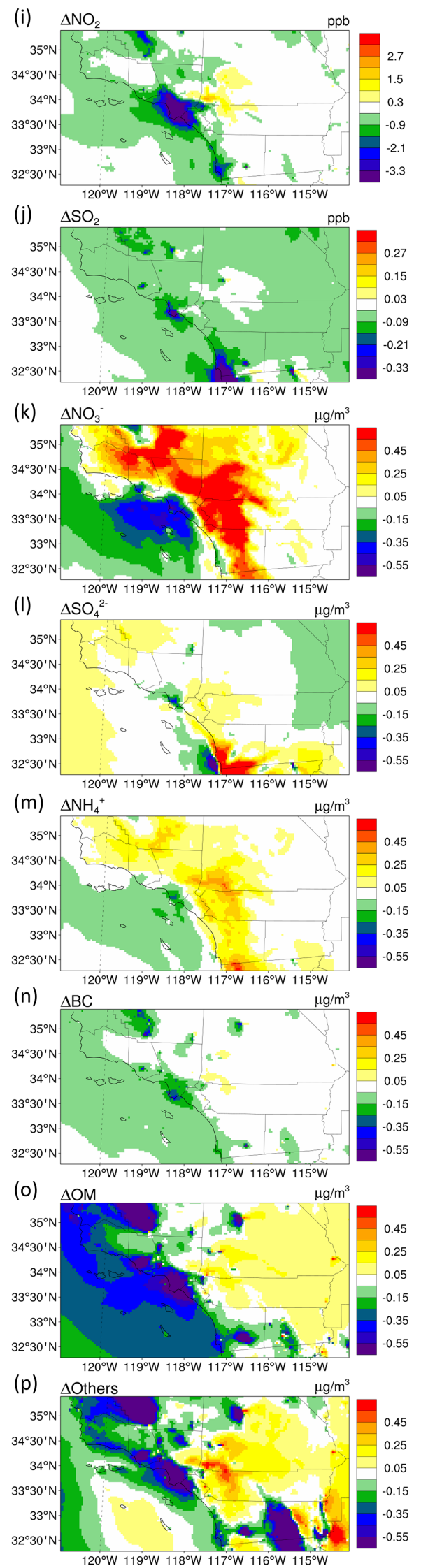

Figure 7. The same as Fig. 6 but for $\mathrm{NO}_{2}, \mathrm{SO}_{2}$, and different $\mathrm{PM}_{2.5}$ chemical components. 
tributions. The overall concentration decrease in these primary chemical components even exceeds that of nitrate; this clearly indicates an important role of primary $\mathrm{PM}_{2.5}$ components in improving $\mathrm{PM}_{2.5}$ air quality during the lockdown period, although the primary $\mathrm{PM}_{2.5}$ emissions have only been reduced by $15 \%$.

The simulated population-weighted $\mathrm{O}_{3}$ concentrations increase noticeably from $38 \mathrm{ppb}$ in the pre-lockdown period

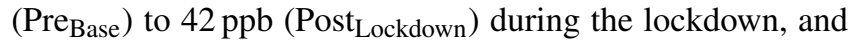
the effects of meteorological changes (i.e., Post $_{\text {Base }}-$ Pre $_{\text {Base }}$ ) play a dominant role in the variation of $\mathrm{O}_{3}$. The $\mathrm{O}_{3}$ level is strongly affected by ambient conditions like temperature and solar radiation (Z. Wang et al., 2015). As the temperature gets warmer and the radiation gets stronger over time, the $\mathrm{O}_{3}$ concentrations are elevated in most areas during the COVID-19 lockdown compared to the pre-lockdown period (Fig. 6d). The emission reductions cause an $\mathrm{O}_{3}$ decrease in rural areas but a slight increase in the urban areas (Figs. 6c and $3 \mathrm{f}, \mathrm{h}$ ), which is consistent with previous findings (Zhao et al., 2019a; T. Y. Wang et al., 2020; Martien et al., 2003; Qin et al., 2004). In urban areas where $\mathrm{NO}_{x}$ emissions are high, a volatile-organic-compound-limited (VOC-limited) regime is seen, while in rural areas, a $\mathrm{NO}_{x}$-limited regime is observed (Martien et al., 2003; Qin et al., 2004). It follows that the decrease in $\mathrm{NO}_{x}$ emissions leads to opposite changes in $\mathrm{O}_{3}$ concentrations in urban and rural areas. The increase and decrease in different areas largely offset each other, resulting in a negligible change in population-weighted $\mathrm{O}_{3}$ concentrations $(0.07 \mathrm{ppb})$ (Fig. $5 \mathrm{~d})$ and a slight decrease in area-averaged $\mathrm{O}_{3}$ concentrations over the modeling domain (0.77 ppb) (Figs. 6c and S5b). Last but not least, the small sensitivity of $\mathrm{O}_{3}$ to emission reductions is also partly explained by the fact that $75 \%$ of the ambient $\mathrm{O}_{3}$ concentration is background $\mathrm{O}_{3}$ (Zhao et al., 2019a; T. Y. Wang et al., 2020).

\subsection{Effects of anthropogenic $\mathrm{NO}_{x}$ and VOC emission reductions on ozone concentration}

Our modeling results showed an increase in $\mathrm{O}_{3}$ in urban areas due to the emission reductions in association with the lockdown during the COVID-19 pandemic. The $\mathrm{O}_{3}$ concentrations are most significantly affected by emissions of $\mathrm{NO}_{x}$ and VOCs (Stewart et al., 2017). To further explore the drivers of the $\mathrm{O}_{3}$ changes and potential approaches to effectively reduce $\mathrm{O}_{3}$ concentrations, we conduct three sensitivity experiments involving $\mathrm{NO}_{x}$ and VOC emission perturbations, as summarized in Table 1. Figure 8 illustrates populationweighted concentrations of simulated $\mathrm{PM}_{2.5}$ components and MDA8 $\mathrm{O}_{3}$ after the COVID-19 lockdown under these sensitivity scenarios. Figure 9 shows the spatial distribution of the differences in MDA8 $\mathrm{O}_{3}$ between the sensitivity scenarios and the Base scenario. Figure 10 shows the concentration time series for the sensitivity scenarios. The first sensitivity experiment is the VOC1.0 scenario, which is the same as Lockdown except that the VOC emissions are kept at the level of the Base scenario (Table 1). This scenario, in combination with the Base and Lockdown scenarios, can be used to evaluate the response of $\mathrm{O}_{3}$ concentrations if the COVID19-induced emission reductions of $\mathrm{NO}_{x}$ and VOC were implemented in sequence. Without the control of VOC emissions in VOC1.0 (Fig. 9a), the increase in urban $\mathrm{O}_{3}$ concentration relative to the Base scenario becomes larger than the Lockdown scenario (Fig. 6c). This confirms our conclusion in the last section that the $\mathrm{NO}_{x}$ emission control elevates urban $\mathrm{O}_{3}$ concentrations under the VOC-limited regime and meanwhile indicates that the VOC control is conducive to $\mathrm{O}_{3}$ decrease. To assess the potential effects of strengthened $\mathrm{NO}_{x}$ and VOC control measures, we conduct two other sensitivity experiments named $\mathrm{NO}_{x} 0.3$ and VOCO.3, which are the same as Lockdown except that the anthropogenic $\mathrm{NO}_{x}$ (for the $\mathrm{NO}_{x} 0.3$ scenario) and VOC (for the VOC0.3 scenario) emissions are further reduced to $30 \%$ of those in the Base scenario. As a $70 \%$ reduction is close to the maximum reductions in $\mathrm{NO}_{x}$ and VOC emissions that could be achieved through the full implementation of technologically and economically feasible control measures (Amann et al., 2020), we select an emission ratio of 0.3 ( $70 \%$ reduction) to represent the potential impact of highly stringent control policies in the future. Figure $8 \mathrm{a}$ and $\mathrm{b}$ show that strengthened $\mathrm{NO}_{x}$ control further reduces the population-weighted concentrations of $\mathrm{PM}_{2.5}$, while further reduction of anthropogenic VOCs helps to decrease the concentration of MDA8 $\mathrm{O}_{3}$. Differences in $\mathrm{O}_{3}$ concentration clearly illustrate different spatial distribution patterns for urban and suburb areas (Fig. 9b, c). For the suburbs with high $\mathrm{O}_{3}$ values, reducing anthropogenic $\mathrm{NO}_{x}$ and VOCs is conducive to the decline of $\mathrm{O}_{3}$ (Fig. 8d). For urban areas, however, strengthened control with anthropogenic $\mathrm{NO}_{x}$ reduced by $70 \%\left(\mathrm{NO}_{x} 0.3\right)$ results in even more $\mathrm{O}_{3}$ increase in the central urban area (Figs. $9 \mathrm{~b}$ and $8 \mathrm{c}$ ). Amplified ozone pollution has also been reported by Sicard et al. (2020) based on their observational studies in four southern European cities and Wuhan, China, associated with $\mathrm{NO}_{x}$ reductions in response to COVID-19. To control $\mathrm{O}_{3}$ concentrations in urban areas, VOC control may be an effective method. While a $\mathrm{NO}_{x}$ emission reduction might cause an increase in $\mathrm{O}_{3}$ concentration, a VOC reduction generally leads to a monotonous reduction of $\mathrm{O}_{3}$ concentrations regardless of the $\mathrm{O}_{3}$ formation regime, as indicated by the classical $\mathrm{O}_{3}$ EKMA isopleth (Fig. 6-1 of National Research Council, 1991, or Fig. 3.2.1 of Donahue, 2018) as well as some recent studies in southern California (Fujita et al., 2013; Collet et al., 2018; Qian et al., 2019). We find that in the VOC0.3 scenario, there is almost no $\mathrm{O}_{3}$ concentration increase relative to the Base scenario, in contrast to a significant urban $\mathrm{O}_{3}$ increase in the Lockdown scenario (Fig. 9c). This means that a $70 \%$ reduction in anthropogenic VOCs can offset the increases in $\mathrm{O}_{3}$ caused by the $28.3 \% \mathrm{NO}_{x}$ reduction during the lockdown. Note that we are specifically looking at the extent of VOC emission reductions that are needed to offset 

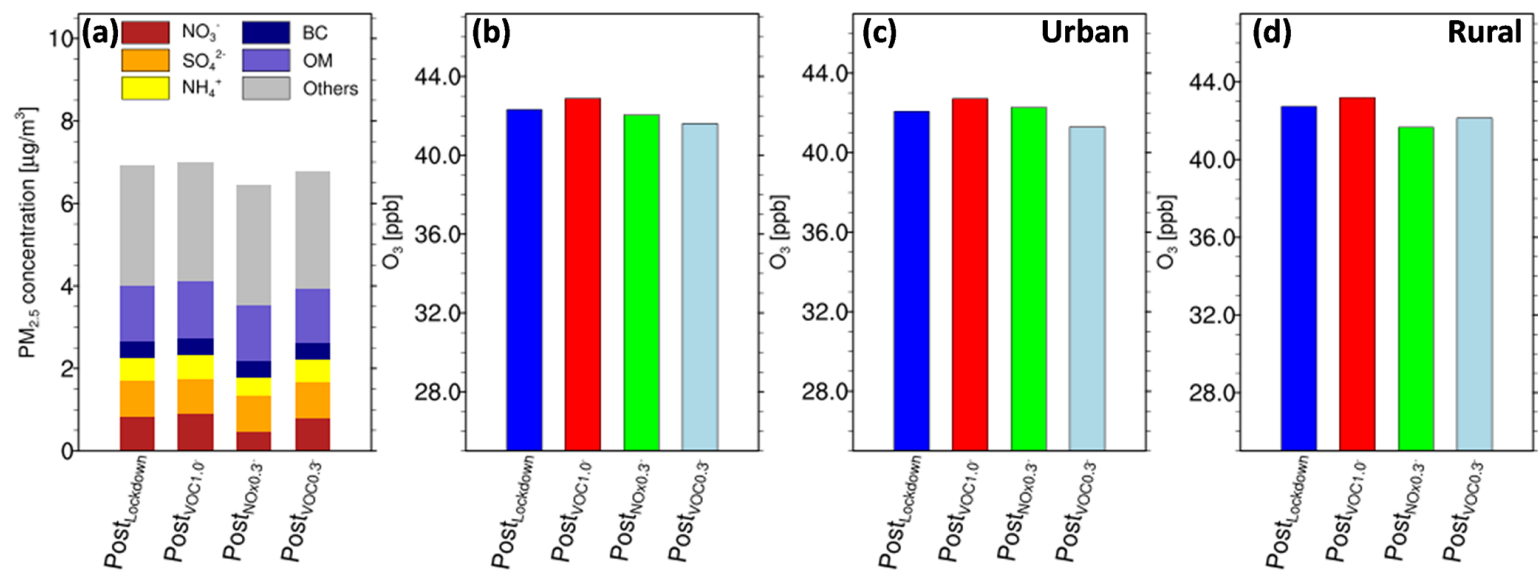

Figure 8. Simulated population-weighted $\mathrm{PM}_{2.5}$ and $\mathrm{O}_{3}$ concentrations under three sensitivity scenarios $\left(\mathrm{VOC} 1.0, \mathrm{NO}_{x} 0.3\right.$, and $\left.\mathrm{VOC} 0.3\right)$ during the lockdown period (19 March to 23 April) over southern California. (a) $\mathrm{PM}_{2.5}$ components, (b) MDA8 $\mathrm{O}_{3}$, and (c) MDA8 $\mathrm{O}_{3}$ over the urban areas, as well as (d) MDA8 $\mathrm{O}_{3}$ over the rural areas. The definitions of all scenarios are summarized in Table 1.

the $28.3 \% \mathrm{NO}_{x}$ reduction caused by the lockdown, which minimizes the complexity due to the nonlinear $\mathrm{O}_{3}$ responses when the $\mathrm{NO}_{x}$ emissions change simultaneously. Furthermore, Wang et al. (2019) found that $75 \%$ of the average $\mathrm{O}_{3}$ concentration in California was due to distant emissions outside the western United States. Many other studies have also revealed that background $\mathrm{O}_{3}$ dominates over the contribution from local emissions in the western US (Huang et al., 2015; Oltmans et al., 2008; Fiore et al., 2014; Emery et al., 2012; Zhang et al., 2011). Therefore, cooperating with other regions and countries in emission reductions may be another way to control $\mathrm{O}_{3}$ in urban areas of southern California.

\section{Conclusion and policy implications}

In this study, we investigated the air quality impact of emission reductions in southern California in association with COVID-19 by employing WRF-Chem to conduct highresolution atmospheric modeling during 18 February to 23 April 2020.

Based on the statistics of activity levels, we first adjusted the emission inventory considering the emission reductions during the COVID-19 lockdown. The adjusted emission inventory is shown to be consistent with the emission inventory based on satellite observations. The simulated magnitude and temporal evolution of the concentrations of the key air pollutants, including $\mathrm{PM}_{2.5}, \mathrm{NO}_{2}, \mathrm{SO}_{2}$, and MDA8 $\mathrm{O}_{3}$, using the adjusted emission inventory agree better with surface observations than simulation results without considering the COVID-19-induced emission reductions. Due to the reduced emissions, the population-weighted concentrations of $\mathrm{NO}_{2}$ and $\mathrm{PM}_{2.5}$ decreased by $27 \%$ and $15 \%$, respectively, in southern California in the 5 weeks after the stay-at-home orders. Emission reductions and meteorological variations contributed about two-thirds and one-third, respectively, to
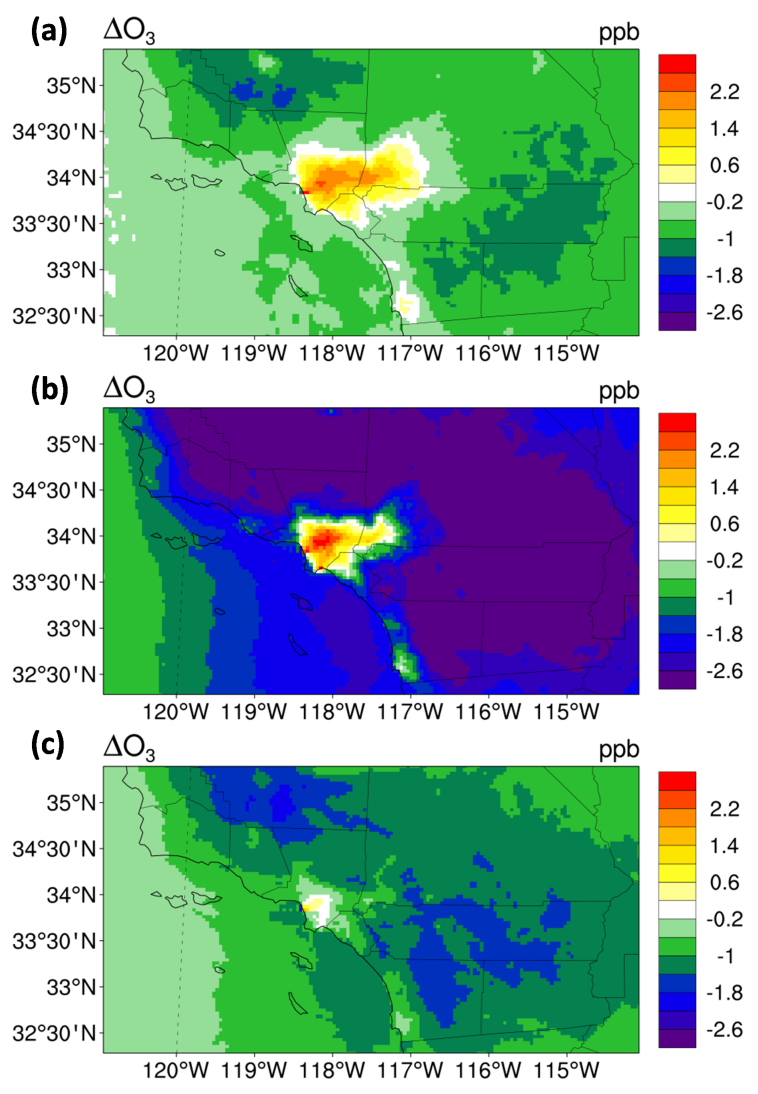

Figure 9. Spatial distribution of the differences in MDA8 $\mathrm{O}_{3}$ between the three sensitivity scenarios and the Base scenario: (a) VOC1.0 minus Base; (b) $\mathrm{NO}_{x} 0.3$ minus Base; (c) VOC0.3 minus Base. The definitions of all scenarios are summarized in Table 1.

the total decrease in population-weighted $\mathrm{PM}_{2.5}$ concentrations before and after the lockdown. For $\mathrm{O}_{3}$ concentration, however, the COVID-19-related emission reductions caused 

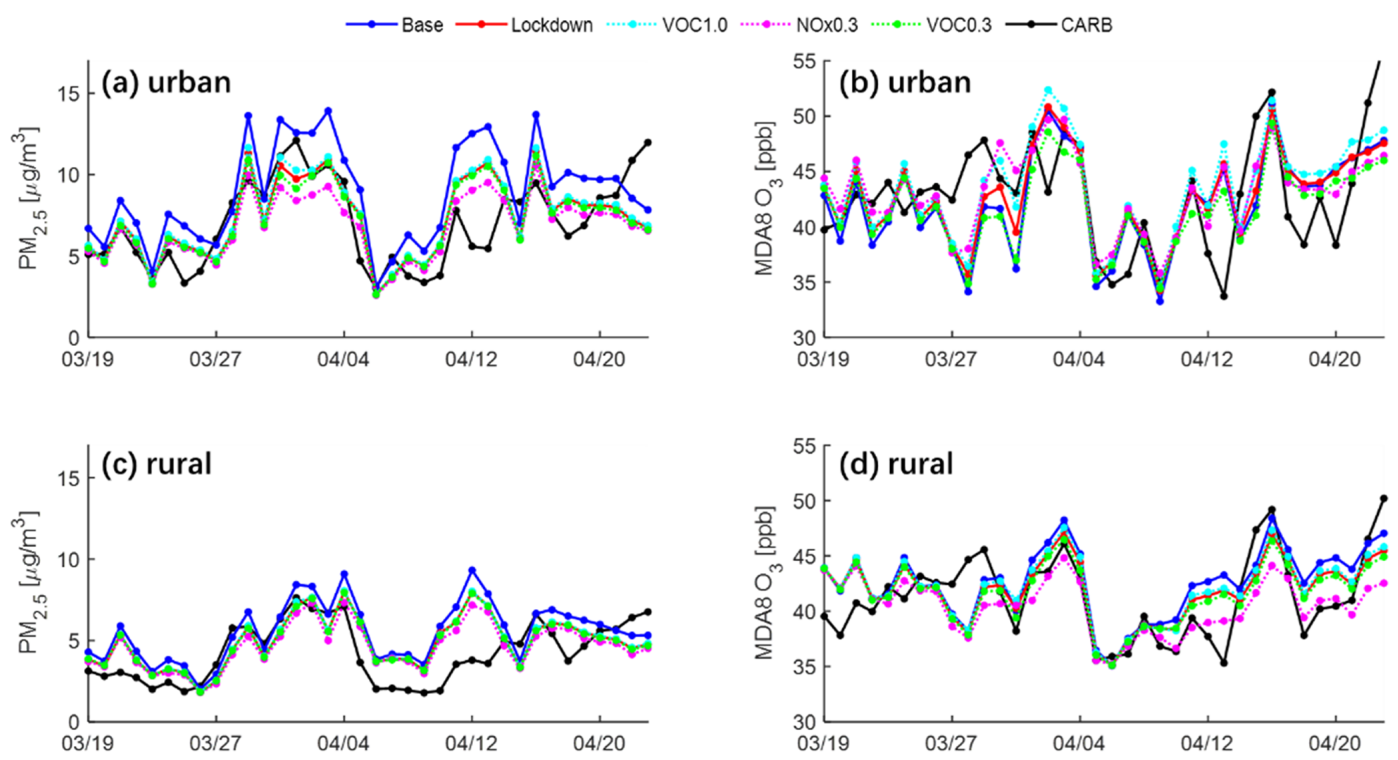

Figure 10. Time series of simulated and observed $\mathrm{PM}_{2.5}$ concentrations (a, c) and $\mathrm{MDA} 8 \mathrm{O}_{3}$ concentrations (b, d) under several sensitivity scenarios averaged across the CARB observational stations over the urban (a, b) and rural (c, d) areas of southern California during the lockdown period (19 March to 23 April). Black lines are surface observations from CARB networks. Blue, red, cyan, magenta, and green lines are simulated results for the Base, Lockdown, $\mathrm{VOC} 1.0, \mathrm{NO}_{x} 0.3$, and VOC0.3 scenarios. The definitions of all scenarios are summarized in Table 1.

a decrease in suburb areas but a slight increase in the urban areas. In order to further explore the effects of anthropogenic $\mathrm{NO}_{x}$ and $\mathrm{VOC}$ emission reductions on $\mathrm{O}_{3}$ concentration, we conducted sensitivity experiments by strengthening VOC and $\mathrm{NO}_{x}$ controls. Our results showed that strengthened control with $\mathrm{NO}_{x}$ reduced by $70 \%\left(\mathrm{NO}_{x} 0.3\right)$ results in even more $\mathrm{O}_{3}$ increase in the central urban area, and anthropogenic VOC control may be an effective method to reduce $\mathrm{O}_{3}$ concentrations in urban areas. A $70 \%$ reduction in anthropogenic VOCs can effectively offset all the increases in $\mathrm{O}_{3}$ caused by $\mathrm{NO}_{x}$ reduction during the lockdown.

Using COVID-19 as an unprecedented experiment with substantial emission reductions from multiple sectors, especially transportation, this study helps to elucidate the complex and nonlinear response of chemical compositions to air pollution control measures and thus provides important insight into the development and optimization of effective air pollution control strategies in southern California. We find that the reduced $\mathrm{NO}_{x}$ emissions $(\sim 28 \%)$ have been almost fully transferred to the reduction in the ambient concentration of $\mathrm{NO}_{2}(\sim 27 \%)$. This further translates into a remarkable reduction in nitrate, which makes the largest contribution to the $\mathrm{PM}_{2.5}$ concentration decrease among all individual chemical components. Therefore, to alleviate $\mathrm{PM}_{2.5}$ pollution, measures focusing on sectors such as transportation, which is among the main sources of $\mathrm{NO}_{x}$ emissions, could be effective. Moreover, we find that a moderate $15 \%$ reduction of primary $\mathrm{PM}_{2.5}$ emissions has resulted in a substantial reduction in ambient $\mathrm{PM}_{2.5}$ concentrations, with the to- tal concentration decreases in all primary $\mathrm{PM}_{2.5}$ components exceeding that of nitrate. Therefore, a strengthened control on primary $\mathrm{PM}_{2.5}$ emissions could be an effective strategy to sustainably mitigate $\mathrm{PM}_{2.5}$ pollution. For $\mathrm{O}_{3}$, reduction of $\mathrm{NO}_{x}$ can effectively reduce high $\mathrm{O}_{3}$ concentrations in suburban areas but may cause an increase in urban concentrations. A $70 \%$ VOC emission reduction is found to fully offset the urban $\mathrm{O}_{3}$ increase caused by the lockdown. Therefore, the reduction in $\mathrm{NO}_{x}$ emissions needs to be accompanied by a well-balanced reduction in VOC emissions to avoid side effects on urban $\mathrm{O}_{3}$ pollution.

Data availability. The data from the California Air Resources Board (CARB) monitoring stations used in the present study can be obtained from https://www.arb.ca.gov/aqmis2/aqdselect.php (California Air Resources Board, 2020). The meteorology observational data obtained from the National Climatic Data Center (NCDC) can be freely downloaded from ftp://ftp.ncdc.noaa.gov/pub/data/noaa/ (NCDC, 2020). Other data needed to support the findings of this study are in the paper and the Supplement. The satellite-based $\mathrm{NO}_{x}$ emission data used in the study can be downloaded freely from https://doi.org/10.25966/9qgv-fe81 (Miyazaki et al., 2019).

Supplement. The supplement related to this article is available online at: https://doi.org/10.5194/acp-21-8693-2021-supplement.

Author contributions. BZ, YG, YiZ, HS, and ZJ designed the research; HS, ZJ, and BZ conducted the research; ZJ, HS, BZ, and 
YG analyzed the results; KM and KWB provided the satellite-based emission data set; ZJ, BZ, HS, and YG wrote the paper with help from XL, YuZ, KM, YiZ, KWB, TS, and KNL.

Competing interests. The authors declare that they have no conflict of interest.

Acknowledgements. Bin Zhao was partially supported by the DOE Atmospheric System Research (ASR) program. Zhe Jiang was partially supported by the National Natural Science Foundation of China (grant no. 41975178), the Youth Innovation Promotion Association of the Chinese Academy of Sciences, and a grant from State Key Laboratory of Resources and Environmental Information System. Yu Gu and Kuo-Nan Liou acknowledge support by NSF AGS-1660587, the NASA TASNNP program, and the NOAADOE CPT program. Yu Gu and Yifang Zhu acknowledge support by LADWP award no. 20200288. Part of this work was conducted at the Jet Propulsion Laboratory, California Institute of Technology, under contract with NASA. Kazuyuki Miyazaki and Kevin W. Bowman acknowledge support by the NASA Atmospheric Composition: Aura Science Team Program (19-AURAST19-0044). We would like to acknowledge high-performance computing support from Cheyenne (https://doi.org/10.5065/D6RX99HX) provided by NCAR's Computational and Information Systems Laboratory, sponsored by the National Science Foundation.

Financial support. This research has been supported by the National Natural Science Foundation of China (grant no. 41975178), the Youth Innovation Promotion Association of the Chinese Academy of Sciences, a grant from State Key Laboratory of Resources and Environmental Information System, the DOE Atmospheric System Research (ASR) program, the National Science Foundation (grant no. AGS-1660587), the NASA TASNNP program, the NOAA-DOE CPT program, the LADWP award (no. 20200288), and the National Aeronautics and Space Administration (Aura Science Team Program (grant no. 19-AURAST190044)).

Review statement. This paper was edited by Zhanqing Li and reviewed by three anonymous referees.

\section{References}

Ahmadov, R., McKeen, S. A., Robinson, A. L., Bahreini, R., Middlebrook, A. M., de Gouw, J. A., Meagher, J., Hsie, E. Y., Edgerton, E., Shaw, S., and Trainer, M.: A volatility basis set model for summertime secondary organic aerosols over the eastern United States in 2006, J. Geophys. Res.-Atmos., 117, D06301, https://doi.org/10.1029/2011jd016831, 2012.

Amann, M., Kiesewetter, G., Schöpp, W., Klimont, Z., Winiwarter, W., Cofala, J., Rafaj, P., Höglund-Isaksson, L., Gomez-Sabriana, A., and Heyes, C.: Reducing global air pollution: the scope for further policy interventions, Philos. T. Roy. Soc. A, 378, 20190331, https://doi.org/10.1098/rsta.2019.0331, 2020.

Archer, C. L., Cervone, G., Golbazi, M., Al Fahel, N., and Hultquist, C.: Changes in air quality and human mobility in the US during the COVID-19 pandemic, Bull. Atmos. Sci. Technol., 1, 491514, https://doi.org/10.1007/s42865-020-00019-0, 2020.

Bashir, M. F., Bilal, B. M., and Komal, B.: Correlation between environmental pollution indicators and COVID-19 pandemic: A brief study in Californian context, Environ. Res., 187, 109652, https://doi.org/10.1016/j.envres.2020.109652, 2020.

Bekbulat, B., Apte, J. S., Millet, D. B., Robinson, A., Wells, K. C., and Marshall, J. D.: $\mathrm{PM}_{2.5}$ and Ozone Air Pollution Levels Have Not Dropped Consistently Across the US Following Societal Covid Response, ChemRxiv, 12275603, https://doi.org/10.26434/chemrxiv.12275603.v7, 2020.

California Air Resources Board: Emission Inventory Data, 2012 Base Year Emissions, Sacramento, California, available at: https: //ww3.arb.ca.gov/ei/emissiondata.htm (last access: 5 July 2018), 2017.

California Air Resources Board: CEPAM: Emission Projections By Summary Category, available at: https://www.arb.ca.gov/app/ emsinv/fcemssumcat/fcemssumcat2016.php, last access: 1 October 2018.

California Air Resources Board: Air Quality Data, available at: https://www.arb.ca.gov/aqmis2/aqdselect.php, last access: 19 May 2020.

California Energy Commission: Energy Insights, available at: https://www.energy.ca.gov/data-reports/energy-insights, last access: 1 July 2020a.

California Energy Commission: Weekly Fuels Watch Report, available at: https://ww2.energy.ca.gov/almanac/petroleum data/fuels_watch/index_cms.html, last access: 1 July 2020 b.

Chen, D., Li, Q., Stutz, J., Mao, Y., Zhang, L., Pikelnaya, O., Tsai, J. Y., Haman, C., Lefer, B., and Rappenglück, B.: WRF-Chem simulation of $\mathrm{NO}_{x}$ and $\mathrm{O}_{3}$ in the LA basin during CalNex-2010, Atmos. Environ., 81, 421-432, 2013.

Chen, L.-W. A., Chien, L.-C., Li, Y., and Lin, G.: Nonuniform impacts of COVID-19 lockdown on air quality over the United States, Sci. Total Environ., 745, 141105, https://doi.org/10.1016/j.scitotenv.2020.141105, 2020.

Chu, B., Zhang, S., Liu, J., Ma, Q., and He, H.: Significant concurrent decrease in $\mathrm{PM}_{2.5}$ and $\mathrm{NO}_{2}$ concentrations in China during COVID-19 epidemic, J. Environ. Sci., 99, 346-353, https://doi.org/10.1016/j.jes.2020.06.031, 2021.

Collet, S., Kidokoro, T., Karamchandani, P., and Shah, T.: Future-year ozone isopleths for South Coast, San Joaquin Valley, and Maryland, Atmosphere-Basel, 9, 354, https://doi.org/10.3390/atmos9090354, 2018.

Copat, C., Cristaldi, A., Fiore, M., Grasso, A., Zuccarello, P., Signorelli, S. S., Conti, G. O., and Ferrante, M.: The role of air pollution (PM and $\mathrm{NO}_{2}$ ) in COVID-19 spread and lethality: a systematic review, Environ. Res., 191, 110129, https://doi.org/10.1016/j.envres.2020.110129, 2020.

Donahue, N. M.: Air pollution and air quality, in: Green Chemistry, Elsevier, 151-176, https://doi.org/10.1016/B978-0-12-8092705.00007-8, 2018.

Emery, C., Tai, E., and Yarwood, G.: Enhanced meteorological modeling and performance evaluation for two texas episodes, in: Report to the Texas Natural Resources Conservation Commis- 
sion, ENVIRON International Corporation, Novato, California, USA, 2001.

Emery, C., Jung, J., Downey, N., Johnson, J., Jimenez, M., Yarvvood, G., and Morris, R.: Regional and global modeling estimates of policy relevant background ozone over the United States, Atmos. Environ., 47, 206-217, https://doi.org/10.1016/j.atmosenv.2011.11.012, 2012.

Fiore, A. M., Oberman, J. T., Lin, M. Y., Zhang, L., Clifton, O. E., Jacob, D. J., Naik, V., Horowitz, L. W., Pinto, J. P., and Milly, G. P.: Estimating North American background ozone in U.S. surface air with two independent global models: Variability, uncertainties, and recommendations, Atmos. Environ., 96, 284-300, https://doi.org/10.1016/j.atmosenv.2014.07.045, 2014.

Fujita, E. M., Campbell, D. E., Stockwell, W. R., and Lawson, D. R.: Past and future ozone trends in California's South Coast Air Basin: Reconciliation of ambient measurements with past and projected emission inventories, J. Air Waste Manage., 63, 54-69, 2013.

Goldberg, D. L., Anenberg, S. C., Griffin, D., McLinden, C. A., Lu, Z., and Streets, D. G.: Disentangling the impact of the COVID-19 lockdowns on urban $\mathrm{NO}_{2}$ from natural variability, Geophys. Res. Lett., 47, e2020GL089269, https://doi.org/10.1029/2020GL089269, 2020.

Guo, L., Chen, J., Luo, D., Liu, S., Lee, H. J., Motallebi, N., Fong, A., Deng, J., Rasool, Q. Z., and Avise, J. C.: Assessment of Nitrogen Oxide Emissions and San Joaquin Valley $\mathrm{PM}_{2.5}$ Impacts From Soils in California, J. Geophys. Res.-Atmos., 125, e2020JD033304, https://doi.org/10.1029/2020JD033304, 2020.

Hong, A., Schweitzer, L., Yang, W., and Marr, L. C.: Impact of temporary freeway closure on regional air quality: a lesson from Carmageddon in Los Angeles, United States, Environ. Sci. Technol., 49, 3211-3218, 2015.

Huang, M., Bowman, K. W., Carmichael, G. R., Lee, M., Chai, T. F., Spak, S. N., Henze, D. K., Darmenov, A. S., and da Silva, A. M.: Improved western US background ozone estimates via constraining nonlocal and local source contributions using Aura TES and OMI observations, J. Geophys. Res.-Atmos., 120, 3572-3592, https://doi.org/10.1002/2014jd022993, 2015.

Huang, X., Ding, A., Gao, J., Zheng, B., Zhou, D., Qi, X., Tang, R., Wang, J., Ren, C., and Nie, W.: Enhanced secondary pollution offset reduction of primary emissions during COVID-19 lockdown in China, Natl. Sci. Rev., 8, nwaa137, https://doi.org/10.1093/nsr/nwaa137, 2021.

Le, T., Wang, Y., Liu, L., Yang, J., Yung, Y. L., Li, G., and Seinfeld, J. H.: Unexpected air pollution with marked emission reductions during the COVID-19 outbreak in China, Science, 369, 702-706, 2020.

Liu, F., Page, A., Strode, S. A., Yoshida, Y., Choi, S., Zheng, B., Lamsal, L. N., Li, C., Krotkov, N. A., and Eskes, H.: Abrupt decline in tropospheric nitrogen dioxide over China after the outbreak of COVID-19, Science Advances, 6, eabc2992, https://doi.org/10.1126/sciadv.abc2992, 2020.

Marlier, M. E., Xing, J., Zhu, Y., and Wang, S.: Impacts of COVID-19 response actions on air quality in China, Environ. Res. Commun., 2, 075003, https://doi.org/10.1088/25157620/aba425, 2020.

Marsh, D. R., Mills, M. J., Kinnison, D. E., Lamarque, J. F., Calvo, N., and Polvani, L. M.: Climate Change from 1850 to 2005
Simulated in CESM1(WACCM), J. Climate, 26, 7372-7391, https://doi.org/10.1175/jcli-d-12-00558.1, 2013.

Martien, P. T., Harley, R. A., Milford, J. B., and Russell, A. G.: Evaluation of incremental reactivity and its uncertainty in southern California, Environ. Sci. Technol., 37, 1598-1608, 2003.

Menut, L., Bessagnet, B., Siour, G., Mailler, S., Pennel, R., and Cholakian, A.: Impact of lockdown measures to combat Covid19 on air quality over western Europe, Sci. Total Environ., 741, 140426, https://doi.org/10.1016/j.scitotenv.2020.140426, 2020.

Miyazaki, K., Bowman, K., Sekiya, T., Eskes, H., Boersma, F., Worden, H., Livesey, N., Payne, V. H., Sudo, K., Kanaya, Y., Takigawa, M., and Ogochi, K.: Chemical Reanalysis Products, Jet Propulsion Laboratory, https://doi.org/10.25966/9qgv-fe81, 2019.

Miyazaki, K., Bowman, K., Sekiya, T., Eskes, H., Boersma, F., Worden, H., Livesey, N., Payne, V. H., Sudo, K., Kanaya, Y., Takigawa, M., and Ogochi, K.: Updated tropospheric chemistry reanalysis and emission estimates, TCR-2, for 2005-2018, Earth Syst. Sci. Data, 12, 2223-2259, https://doi.org/10.5194/essd-122223-2020, 2020a.

Miyazaki, K., Bowman, K., Sekiya, T., Jiang, Z., Chen, X., Eskes, H., Ru, M., Zhang, Y., and Shindell, D.: Air Quality Response in China Linked to the 2019 Novel Coronavirus (COVID19) Lockdown, Geophys. Res. Lett., 47, e2020GL089252, https://doi.org/10.1029/2020GL089252, 2020b.

National Climatic Data Center (NCDC): Global Meteorology Observational Data, available at: ftp://ftp.ncdc.noaa.gov/pub/data/ noaa/, last access: 19 May 2020.

National Research Council: Rethinking the Ozone Problem in Urban and Regional Air Pollution, The National Academies Press, Washington, D.C., USA, https://doi.org/10.17226/1889, 1991.

Oltmans, S. J., Lefohn, A. S., Harris, J. M., and Shadwick, D. S.: Background ozone levels of air entering the west coast of the US and assessment of longer-term changes, Atmos. Environ., 42, 6020-6038, https://doi.org/10.1016/j.atmosenv.2008.03.034, 2008.

Ordóñez, C., Garrido-Perez, J. M., and García-Herrera, R.: Early spring near-surface ozone in Europe during the COVID-19 shutdown: Meteorological effects outweigh emission changes, Sci. Total Environ., 747, 141322, https://doi.org/10.1016/j.scitotenv.2020.141322, 2020.

Pan, S., Jung, J., Li, Z., Hou, X., Roy, A., Choi, Y., and Gao, H. O.: Air Quality Implications of COVID19 in California, Sustainability-Basel, 12, 7067, https://doi.org/10.3390/su12177067, 2020.

Pathakoti, M., Muppalla, A., Hazra, S., Dangeti, M., Shekhar, R., Jella, S., Mullapudi, S. S., Andugulapati, P., and Vijayasundaram, U.: An assessment of the impact of a nationwide lockdown on air pollution - a remote sensing perspective over India, Atmos. Chem. Phys. Discuss. [preprint], https://doi.org/10.5194/acp-2020-621, 2020.

Qian, Y., Henneman, L. R., Mulholland, J. A., and Russell, A. G.: Empirical development of ozone isopleths: Applications to Los Angeles, Environ. Sci. Tech. Let., 6, 294-299, 2019.

Qin, Y., Tonnesen, G., and Wang, Z.: One-hour and eight-hour average ozone in the California South Coast air quality management district: trends in peak values and sensitivity to precursors, Atmos. Environ., 38, 2197-2207, 2004. 
Ratcliffe, M., Burd, C., Holder, K., and Fields, A.: Defining rural at the US Census Bureau, American Community Survey and Geography Brief, US Census Bureau, Washington, DC, USA, 1 p., 2016.

Sarwar, G., Luecken, D., Yarwood, G., Whitten, G. Z., and Carter, W. P. L.: Impact of an updated carbon bond mechanism on predictions from the CMAQ modeling system: Preliminary assessment, J. Appl. Meteorol. Clim., 47, 3-14, https://doi.org/10.1175/2007jamc1393.1, 2008.

Sharma, S., Zhang, M., Gao, J., Zhang, H., and Kota, S. H.: Effect of restricted emissions during COVID-19 on air quality in India, Sci. Total Environ., 728, 138878, https://doi.org/10.1016/j.scitotenv.2020.138878, 2020.

Shi, H. R., Jiang, Z., Zhao, B., Li, Z. J., Chen, Y., Gu, Y., Jiang, J. H., Lee, M., Liou, K. N., Neu, J. L., Payne, V. H., Su, H., Wang, Y., Witek, M., and Worden, J.: Modeling Study of the Air Quality Impact of Record-Breaking Southern California Wildfires in December 2017, J. Geophys. Res.-Atmos., 124, 65546570, https://doi.org/10.1029/2019jd030472, 2019.

Shi, X. and Brasseur, G. P.: The Response in Air Quality to the Reduction of Chinese Economic Activities during the COVID-19 Outbreak, Geophys. Res. Lett., 47, e2020GL088070, https://doi.org/10.1029/2020GL088070, 2020.

Shirmohammadi, F., Hasheminassab, S., Saffari, A., Schauer, J. J., Delfino, R. J., and Sioutas, C.: Fine and ultrafine particulate organic carbon in the Los Angeles basin: Trends in sources and composition, Sci. Total Environ., 541, 1083-1096, 2016.

Sicard, P., De Marco, A., Agathokleous, E., Feng, Z., Xu, X., Paoletti, E., Rodriguez, J. J. D., and Calatayud, V.: Amplified ozone pollution in cities during the COVID-19 lockdown, Sci. Total Environ., 735, 139542, https://doi.org/10.1016/j.scitotenv.2020.139542, 2020.

Stewart, D. R., Saunders, E., Perea, R. A., Fitzgerald, R., Campbell, D. E., and Stockwell, W. R.: Linking air quality and human health effects models: an application to the Los angeles air basin, Environmental Health Insights, 11, 1178630217737551 , https://doi.org/10.1177/1178630217737551, 2017.

US Environmental Protection Agency: Air Pollutant Emissions Trends Data, available at: https://www.epa.gov/ air-emissions-inventories/air-pollutant-emissions-trends-data, last access: 10 December 2018a.

US Environmental Protection Agency: National Emissions Inventory (NEI), available at: https://www.epa.gov/ air-emissions-inventories/national-emissions-inventory-nei, last access: 10 December 2018 b.

Wang, K., Zhang, Y., Yahya, K., Wu, S. Y., and Grell, G.: Implementation and initial application of new chemistry-aerosol options in WRF/Chem for simulating secondary organic aerosols and aerosol indirect effects for regional air quality, Atmos. Environ., 115, 716-732, https://doi.org/10.1016/j.atmosenv.2014.12.007, 2015.

Wang, P., Chen, K., Zhu, S., Wang, P., and Zhang, H.: Severe air pollution events not avoided by reduced anthropogenic activities during COVID-19 outbreak, Resour. Conserv. Recy., 158, 104814, https://doi.org/10.1016/j.resconrec.2020.104814, 2020.

Wang, T., Zhao, B., Liou, K.-N., Gu, Y., Jiang, Z., Song, K., Su, H., Jerrett, M., and Zhu, Y.: Mortality burdens in California due to air pollution attributable to local and nonlocal emissions, Environ.
Int., 133, 105232, https://doi.org/10.1016/j.envint.2019.105232, 2019.

Wang, T. Y., Jiang, Z., Zhao, B., Gu, Y., Liou, K. N., Kalandiyur, N., Zhang, D., and Zhu, Y. F.: Health co-benefits of achieving sustainable net-zero greenhouse gas emissions in California, Nature Sustainability, 3, 597-605, https://doi.org/10.1038/s41893-0200520-y, 2020.

Wang, Z., Li, Y., Chen, T., Zhang, D., Sun, F., Wei, Q., Dong, X., Sun, R., Huan, N., and Pan, L.: Ground-level ozone in urban Beijing over a 1-year period: Temporal variations and relationship to atmospheric oxidation, Atmos. Res., 164, 110-117, 2015.

Warneke, C., De Gouw, J. A., Edwards, P. M., Holloway, J. S., Gilman, J. B., Kuster, W. C., Graus, M., Atlas, E., Blake, D., and Gentner, D. R.: Photochemical aging of volatile organic compounds in the Los Angeles basin: Weekday-weekend effect, J. Geophys. Res.-Atmos., 118, 5018-5028, 2013.

Watanabe, S., Hajima, T., Sudo, K., Nagashima, T., Takemura, T., Okajima, H., Nozawa, T., Kawase, H., Abe, M., Yokohata, T., Ise, T., Sato, H., Kato, E., Takata, K., Emori, S., and Kawamiya, M.: MIROC-ESM 2010: model description and basic results of CMIP5-20c3m experiments, Geosci. Model Dev., 4, 845-872, https://doi.org/10.5194/gmd-4-845-2011, 2011.

World Health Organization: WHO Coronavirus Disease (COVID19) Dashboard: https://www.who.int/emergencies/diseases/ novel-coronavirus-2019/situation-reports/, last access: 13 November 2020.

Yarwood, G., Rao, S., Yocke, M., and Whitten, G. Z.: Final Reportupdates to the Carbon Bond Chemical Mechanism: CB05 (RT04-00675), Yocke and Co., Novato, California, USA, 246 pp., 2005.

Zhang, L., Jacob, D. J., Downey, N. V., Wood, D. A., Blewitt, D., Carouge, C. C., van Donkelaar, A., Jones, D. B. A., Murray, L. T., and Wang, Y. X.: Improved estimate of the policy-relevant background ozone in the United States using the GEOS-Chem global model with $1 / 2^{\circ} \times 2 / 3^{\circ}$ horizontal resolution over North America, Atmos. Environ., 45, 6769-6776, https://doi.org/10.1016/j.atmosenv.2011.07.054, 2011

Zhao, B., Wang, S. X., Xing, J., Fu, K., Fu, J. S., Jang, C., Zhu, Y., Dong, X. Y., Gao, Y., Wu, W. J., Wang, J. D., and Hao, J. M.: Assessing the nonlinear response of fine particles to precursor emissions: development and application of an extended response surface modeling technique v1.0, Geosci. Model Dev., 8, 115128, https://doi.org/10.5194/gmd-8-115-2015, 2015.

Zhao, B., Wan, T. Y., Jiang, Z., Gu, Y., Liou, K. N., Kalandiyur, N., Gao, Y., and Zhu, Y. F.: Air Quality and Health Cobenefits of Different Deep Decarbonization Pathways in California, Environ. Sci. Technol., 53, 7163-7171, https://doi.org/10.1021/acs.est.9b02385, 2019a.

Zhao, B., Wang, S., Ding, D., Wu, W., Chang, X., Wang, J., Xing, J., Jang, C., Fu, J. S., and Zhu, Y.: Nonlinear relationships between air pollutant emissions and $\mathrm{PM}_{2.5}$-related health impacts in the Beijing-Tianjin-Hebei region, Sci. Total Environ., 661, 375-385, 2019b.

Zhao, Y., Zhang, K., Xu, X., Shen, H., Zhu, X., Zhang, Y., Hu, Y., and Shen, G.: Substantial Changes in Nitrate Oxide and Ozone after Excluding Meteorological Impacts during the COVID-19 Outbreak in Mainland China, Environ. Sci. Tech. Let., 7, 402408, 2020. 